\title{
Investigating the applicability of emergent constraints
}

\author{
Alexander J. Winkler ${ }^{1,2}$, Ranga B. Myneni ${ }^{3}$, and Victor Brovkin ${ }^{1}$ \\ ${ }^{1}$ Max Planck Institute for Meteorology, Bundesstrasse 53, 20146 Hamburg, Germany \\ ${ }^{2}$ International Max Planck Research School on Earth System Modelling, \\ Bundesstrasse 53, 20146 Hamburg, Germany \\ ${ }^{3}$ Department of Earth and Environment, Boston University, Boston, Massachusetts 02215, USA
}

Correspondence: Alexander J. Winkler (alexander.winkler@mpimet.mpg.de)

Received: 19 September 2018 - Discussion started: 21 November 2018

Revised: 11 July 2019 - Accepted: 25 July 2019 - Published: 21 August 2019

\begin{abstract}
Recent research on emergent constraints (ECs) has delivered promising results in narrowing down uncertainty in climate predictions. The method utilizes a measurable variable (predictor) from the recent historical past to obtain a constrained estimate of change in an entity of interest (predictand) at a potential future $\mathrm{CO}_{2}$ concentration (forcing) from multi-model projections. This procedure first critically depends on an accurate estimation of the predictor from observations and models and second on a robust relationship between inter-model variations in the predictor-predictand space. Here, we investigate issues related to these two themes in a carbon cycle case study using observed vegetation greening sensitivity to $\mathrm{CO}_{2}$ forcing as a predictor of change in photosynthesis (gross primary productivity, GPP) for a doubling of preindustrial $\mathrm{CO}_{2}$ concentration. Greening sensitivity is defined as changes in the annual maximum of green leaf area index $\left(\mathrm{LAI}_{\max }\right)$ per unit $\mathrm{CO}_{2}$ forcing realized through its radiative and fertilization effects. We first address the question of how to realistically characterize the predictor of a large area (e.g., greening sensitivity in the northern high-latitude region) from pixel-level data. This requires an investigation into uncertainties in the observational data source and an evaluation of the spatial and temporal variability in the predictor in both the data and model simulations. Second, the predictorpredictand relationship across the model ensemble depends on a strong coupling between the two variables, i.e., simultaneous changes in GPP and $\mathrm{LAI}_{\max }$. This coupling depends in a complex manner on the magnitude (level), time rate of application (scenarios), and effects (radiative and/or fertilization) of $\mathrm{CO}_{2}$ forcing. We investigate how each one of these three aspects of forcing can affect the EC estimate of the predictand ( $\Delta \mathrm{GPP})$. Our results show that uncertainties in the EC method primarily originate from a lack of predictor comparability between observations and models, the observational data source, and temporal variability of the predictor. The disagreement between models on the mechanistic behavior of the system under intensifying forcing limits the EC applicability. The discussed limitations and sources of uncertainty in the EC method go beyond carbon cycle research and are generally applicable in Earth system sciences.
\end{abstract}

\section{Introduction}

Earth system models (ESMs) are powerful tools to predict responses to a variety of forcings such as an increasing atmospheric concentration of greenhouse gases and other agents of radiative forcing (Klein and Hall, 2015). Still, long-term ESM projections of climate change have substantial uncertainties. This can be due to poorly understood processes in some cases and to missing or simplified representations called parameterizations in others (Flato et al., 2013; Klein and Hall, 2015; Knutti et al., 2017). Certain important processes, especially in the atmosphere, happen at spatial scales finer than can possibly be represented in current ESMs. Consequently, various phenomena in the system ranging from local extreme precipitation events to large-scale climate modes can be poorly simulated (Flato et al., 2013). Errors propagate and can be amplified through feedbacks among interacting components in the Earth system, resulting in biases whose 
origins can be difficult to identify (Flato et al., 2013). Furthermore, an inherent component of the Earth climatic system, its internal natural variability, is complicated to represent and simulate in models (Flato et al., 2013; Klein and Hall, 2015).

Model intercomparison projects explore these uncertainties by coordinating a wide range of simulation setups focusing on internal variability, boundary conditions, and parameterizations (Taylor et al., 2012; Flato et al., 2013; Eyring et al., 2016; Knutti et al., 2017). Models developed at various institutions are driven with the same forcing information (e.g., historical forcing) or with identical idealized boundary conditions. However, each modeling group decides which of the processes to consider and implement in their ESM. The conventional approach of handling these multi-model ensembles is to use unweighted ensemble averages (Knutti, 2010; Knutti et al., 2017). This assumes that the models are independent of one another and equally good at simulating the climate system (Flato et al., 2013; Knutti et al., 2017). The large spread between model projections suggests that this assumption is not valid. Therefore, alternate methods have been developed to extract results more accurate than multi-model averages (e.g., model weighting scheme based on performance and interdependence; Knutti et al., 2017). The concept of emergent constraints arises in this context, namely as a method to reduce uncertainty in ESM projections relying on historical simulations and observations (Hall and Qu, 2006; Boé et al., 2009; Cox et al., 2013; Klein and Hall, 2015; Cox et al., 2018).

The two key parts of a method based on emergent constraint (EC) are a linear relationship arising from the collective behavior of a multi-model ensemble and an observational estimate for imposing the said constraint (Fig. 1). The linear relationship is a physically (or physiologically) based correlation between inter-model variations in an observable entity of the contemporary climate system (predictor) and a projected variable (predictand) that is difficult to observe or not observable at all. Combining the emergent linear relationship with observations of the predictor sets a constraint on the predictand (Cox et al., 2013; Flato et al., 2013; Klein and Hall, 2015; Knutti et al., 2017). Many such ECs have been identified and reported, as briefly summarized below.

Hall and Qu (2006) proposed a constraint on projections of snow albedo the feedback based on the correlation between large inter-model variations in feedback strength of the current seasonal cycle. The EC was first established for the CMIP3 ensemble and confirmed for phase five of the Coupled Model Intercomparison Project (CMIP5; Flato et al., 2013; Qu and Hall, 2014). Several EC studies followed with the goal of reducing uncertainty in projections of the cloud feedback under global warming, as reviewed by Klein and Hall (2015). It is thought that erroneous representation of low-cloud feedback in ESMs essentially contributes to the large uncertainty in equilibrium climate sensitivity (ECS; 1.5 to $5 \mathrm{~K}$ ), i.e., warming for a doubling of preindustrial

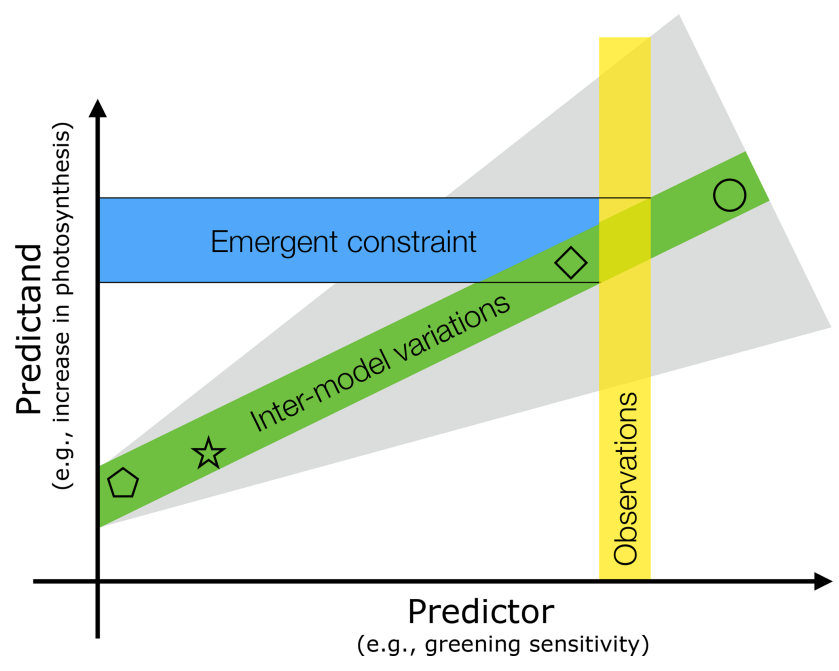

Figure 1. Schematic depiction of the emergent constraint (EC) method and factors affecting the uncertainty of the constrained estimate. The predictor ( $x$ axis) is change in the annual maximum of green leaf area index $\left(\mathrm{LAI}_{\max }\right)$ due to unit forcing $\left(\mathrm{CO}_{2}\right.$ increase and associated climatic changes) during a representative historical period. It is termed greening sensitivity in this study. The predictand ( $y$ axis) is projected change in gross primary productivity (GPP) in response to rising $\mathrm{CO}_{2}$ concentration (e.g., for a doubling of the preindustrial level). Both the predictor and predictand refer to large area values: in this case, the entire northern high latitudes (NHLs). Inter-model variations (each symbol represents a model) in matching pairs of predictors and predictands result in a linear relationship between the two (green band); i.e., the ratio (predictand / predictor) is approximately constant across the model ensemble. The slope depends on forcing attributes (gray shading), such as its level $\left(\mathrm{CO}_{2}\right.$ concentration; Sect. 3.4), time rate of application (scenarios such as various RCPs; Sect. 3.4), and different effects (i.e., fertilization, radiative forcing; Sect. 3.5). The observed sensitivity (vertical yellow bar) is used to find the constrained estimate of the predictand (i.e., change in GPP). The ability to accurately estimate the predictor depends on the source of observational data (Sect. 3.1) and its spatial (Sect. 3.2) and temporal variability (Sect. 3.3). Observed (yellow bar) and modeled predictor values ( $x$ coordinate of symbols) must be obtained from matching time periods, i.e., at the same level of historical forcing, to ensure comparability (Sect. 3.3 and 3.4). All these factors, together with the goodness of fit of intermodel variations (width of green shading), finally define the uncertainty of the derived constrained estimate (blue horizontal bar with black solid lines depicting the upper and lower bound of uncertainty).

atmospheric $\mathrm{CO}_{2}$ concentration $\left(2 \times \mathrm{CO}_{2}\right.$; Sherwood et al., 2014; Klein and Hall, 2015). Recently, Cox et al. (2018) presented a different approach to constrain ECS based on its relationship to the variability of global temperatures during the recent historical warming period. They reported a constrained ECS estimate of $2.8 \mathrm{~K}$ for $2 \times \mathrm{CO}_{2}(66 \%$ confidence limits of 2.2-3.4 K).

The concept of EC also found its way into the field of carbon cycle projections. A series of studies analyzed the ex- 
tent to which interannual atmospheric $\mathrm{CO}_{2}$ variability can serve as a predictor of the long-term temperature sensitivity of terrestrial tropical carbon storage. Cox et al. (2013) and Wenzel et al. (2014) reported an emergent linear relationship, although with different slopes for CMIP3 and CMIP5 ensembles, resulting in slightly divergent constrained estimates (CMIP3: $-53 \pm 17 \mathrm{Pg} \mathrm{C} \mathrm{K}^{-1}$, CMIP5: $-44 \pm 14 \mathrm{Pg} \mathrm{C} \mathrm{K}^{-1}$ ). Wang et al. (2014), however, were unable to detect a similar relationship between the proposed predictor and predictand. Recently, Lian et al. (2018) presented an EC estimate of the global ratio of transpiration to total terrestrial evapotranspiration $(T / E T)$, which is substantially higher $(0.62 \pm 0.06)$ than the unconstrained value $(0.41 \pm 0.11)$. For the marine tropical carbon cycle, Kwiatkowski et al. (2017) identified an emergent relationship between the long-term sensitivity of tropical ocean net primary production (NPP) to rising sea surface temperature (SST) in the equatorial zone and the interannual sensitivity of NPP to El Niño-Southern Oscillationdriven SST anomalies. Tropical NPP is projected to decrease by $3 \pm 1 \%$ for a $1 \mathrm{~K}$ increase in equatorial SST according to the observational constraint.

Similar results were reported for modeled extratropical terrestrial carbon fixation in a $2 \times \mathrm{CO}_{2}$ world. Plant productivity is expected to increase due to the fertilizing and radiative effects of a rising atmospheric $\mathrm{CO}_{2}$ concentration. Wenzel et al. (2016) focused on constraining the $\mathrm{CO}_{2}$ fertilization effect on plant productivity in the northern high latitudes $\left(60-90^{\circ} \mathrm{N}, \mathrm{NHLs}\right)$ and the entire extratropical area in the Northern Hemisphere $\left(30-90^{\circ} \mathrm{N}\right)$ using the seasonal amplitude of long-term $\mathrm{CO}_{2}$ measurements at different latitudes. They presented a linear relationship between the sensitivity of $\mathrm{CO}_{2}$ amplitude to a rising atmospheric $\mathrm{CO}_{2}$ concentration and the relative increase in zonally averaged gross primary production (GPP) for $2 \times \mathrm{CO}_{2}$. The observed $\mathrm{CO}_{2}$ amplitude sensitivities at respective stations provide a constraint on the increase in GPP due to the $\mathrm{CO}_{2}$ fertilization effect, namely $37 \% \pm 9 \%$ and $32 \% \pm 9 \%$ for $2 \times \mathrm{CO}_{2}$ in the NHL and extratropical region, respectively.

Focusing on the NHLs, Winkler et al. (2019) investigated how both effects of $\mathrm{CO}_{2}$ enhance plant productivity while assessing the feasibility of vegetation greenness changes as a constraint. Enhanced GPP due to the physiological effect and ensuing climate warming is indirectly evident in largescale increases in summertime green leaf area (Myneni et al., 1997a; Zhu et al., 2016). Historical CMIP5 simulations show that the maximum annual leaf area index $\left(\mathrm{LAI}_{\max }\right.$, leaf area per ground area) increases linearly with both $\mathrm{CO}_{2}$ concentration and temperature in NHLs. In all ESMs, these changes in $\mathrm{LAI}_{\max }$ strongly correlate with changes in GPP arising from the combined radiative and physiological effects of $\mathrm{CO}_{2}$ enrichment. Thus, the large variation in modeled historical $\mathrm{LAI}_{\max }$ responses to the effects of $\mathrm{CO}_{2}$ linearly maps to variation in $\triangle \mathrm{GPP}$ at $2 \times \mathrm{CO}_{2}$ in the CMIP5 ensemble. This linear relationship in inter-model variations enables the usage of the observed long-term change in $\mathrm{LAI}_{\max }$ as an $\mathrm{EC}$ on $\triangle \mathrm{GPP}$ at $2 \times \mathrm{CO}_{2}$ in NHLs $\left(3.4 \pm 0.2 \mathrm{Pg} \mathrm{Cyr}^{-1}\right.$ for $2 \times \mathrm{CO}_{2}$; Winkler et al., 2019).

The robustness of these EC estimates is debated, mainly because the EC approach is susceptible to methodological inconsistencies. For example, Cox et al. (2013), Wang et al. (2014), and Wenzel et al. (2015) investigated constraining future terrestrial tropical carbon storage using the same set of models and data. However, they arrived at different EC estimates and divergent conclusions. Some reasons for failure and the essential criteria of the EC approach were described previously (Bracegirdle and Stephenson, 2012b; Klein and Hall, 2015), but this list is far from complete. To account for this gap in the literature, a detailed investigation and description of the EC method in terms of its potential sources of uncertainty and the range of applicability are needed.

Here, we revisit the study of Winkler et al. (2019) and elaborate on key issues concerning the robustness of the EC method. Uncertainty of the constrained estimate depends on (a) the observed predictor and (b) modeled relationship, aside from the goodness of fit of the latter (green shading in Fig. 1). As for (a), the source of observations is an obvious first line of inquiry (Sect. 3.1). The spatial aggregation of data and model simulations introduces uncertainties, as the EC method is applied on large areal values of the predictor and predictand. This is the subject of Sect. 3.2. The observed and modeled predictors are from the historical period. The representativeness, duration, and match between data and models all introduce an uncertainty related to variations in the temporal domain - these are explored in Sect. 3.3. The yellow shading in Fig. 1 represents the total uncertainty on the observed predictor from these three fronts. Regarding (b), the modeled linear relation varies (gray shading in Fig. 1) depending on three attributes of the forcing, i.e., the $\mathrm{CO}_{2}$ concentration change along with its magnitude, rate, and effect (Sect. 3.4 and 3.5). Lessons learned from analyses along these lines are presented in the Conclusion.

\section{Data and methods}

\subsection{Remotely sensed leaf area index}

We used the recently updated version (V1) of the leaf area index dataset (LAI3g) developed by Zhu et al. (2013). It was generated using an artificial neural network (ANN) and the latest version (third generation) of the Global Inventory Modeling and Mapping Studies group (GIMMS) Advanced Very High Resolution Radiometer (AVHRR) normalized difference vegetation index (NDVI) data (NDVI3g). The latter have been corrected for sensor degradation, inter-sensor differences, cloud cover, observational geometry effects due to satellite drift, Rayleigh scattering, and stratospheric volcanic aerosols (Pinzon and Tucker, 2014). This dataset provides global and year-round LAI observations at $15 \mathrm{~d}$ (bimonthly) temporal resolution and $1 / 12^{\circ}$ spatial resolution 
from July 1981 to December 2016. Currently, this is the only available record of such length.

The quality of the previous version (V0) of the LAI3g dataset was evaluated through direct comparisons with ground measurements of LAI, indirectly with other satellitedata-based LAI products, and also through statistical analysis with climatic variables, such as temperature and precipitation variability (Zhu et al., 2013). The LAI3gV0 dataset (and the related fraction of vegetation-absorbed photosynthetically active radiation dataset) has been widely used in various studies (Anav et al., 2013; Piao et al., 2014; Poulter et al., 2014; Forkel et al., 2016; Zhu et al., 2016; Mao et al., 2016; Mahowald et al., 2016; Keenan et al., 2016). The new version, LAI3 $\mathrm{gV} 1$, used in our study is an update of that earlier version.

We also utilized a more reliable but shorter dataset from the Moderate Resolution Imaging Spectroradiometer (MODIS) aboard the NASA Terra satellite (Yan et al., 2016a, b). These data are well calibrated, cloud-screened, and corrected for atmospheric effects, especially tropospheric aerosols. The sensor platform is regularly adjusted to maintain a precise orbit. All algorithms, including the LAI algorithm, are physics based, well tested, and currently producing sixth-generation datasets. The dataset provides global and year-round LAI observations at $16 \mathrm{~d}$ (bimonthly) temporal resolution and $1 / 20^{\circ}$ spatial resolution from 2000 to 2016.

Leaf area index is defined as the one-sided green leaf area per unit ground area in broadleaf canopies and as one-half the green needle surface area in needleleaf canopies in both observational and CMIP5 simulation datasets. It is expressed in square meters and green leaf area per square meter of ground area. Leaf area changes can be represented either by changes in annual maximum LAI (LAI max $_{\text {; }}$ Cook and Pau, 2013), or growing season average LAI. In this study, we use the former because of its ease and unambiguity, as the latter requires quantifying the start and end dates of the growing season, something that is difficult to do accurately in NHLs (Park et al., 2016) with the low-resolution model data. Further, $\mathrm{LAI}_{\max }$ is less influenced by cloudiness and noise; accordingly, it is most useful in investigations of long-term greening and browning trends. The drawback of $\mathrm{LAI}_{\max }$ is the saturation effect at high LAI values (Myneni et al., 2002). However, this is less of a problem in high-latitudinal ecosystems that are less densely vegetated compared to tropical regions, with LAI $I_{\max }$ values typically in the range of 2 to 3 .

The bimonthly satellite datasets were merged to a monthly temporal resolution by averaging the two composites in the same month and bilinearly remapped to the resolution of the applied reanalysis product $\left(0.5^{\circ} \times 0.5^{\circ}\right.$, CRU TS4.01).

\subsection{Environmental driver variables}

We use time series of temperature and $\mathrm{CO}_{2}$ to derive the observed historical forcing (Sect. 2.4) and climatologies of precipitation and temperature to calculate climatic regimes (Fig. 2). Monthly averages of near-surface air temperature and precipitation are from the latest version of the Climatic Research Unit Time Series dataset (CRU TS4.01). The global data are gridded to $0.5^{\circ} \times 0.5^{\circ}$ resolution (Harris et al., 2014). Global monthly means of atmospheric $\mathrm{CO}_{2}$ concentration are from the GLOBALVIEW-CO2 product (obspack_c02_1_globalviewplus_v2.1_2016_09_02; for details see https://doi.org/10.25925/20190520) provided by the National Oceanic and Atmospheric Administration/Earth System Research Laboratory (NOAA/ESRL).

\subsection{Earth system model simulations}

We analyzed recent climate-carbon simulations of seven ESMs participating in the fifth phase of the Coupled Model Intercomparison Project, CMIP (Taylor et al., 2012). The model-simulated data were obtained from the Earth System Grid Federation, ESGF (https://esgf-data.dkrz.de/projects/ esgf-dkrz/, last access: 21 September 2018). Seven ESMs provide output for the variables of interest (GPP, $\mathrm{CO}_{2}$, LAI, and near-surface air temperature) for simulations titled esmHistorical, RCP4.5, RCP8.5, 1pctCO2, esmFixClim1, and esmFdbk1. It is the same set of models analyzed in Wenzel et al. (2016) and Winkler et al. (2019). The individual model setups and components are illustrated in more detail in various studies, such as Arora et al. (2013), Wenzel et al. (2014), Mahowald et al. (2016), and Winkler et al. (2019).

The esmHistorical simulation spanned the period 1850 to 2005 and was driven by observed conditions such as solar forcing, emissions or concentrations of short-lived species, natural and anthropogenic aerosols or their precursors, land use, and anthropogenic and volcanic influences on atmospheric composition. The models are forced by prescribed anthropogenic $\mathrm{CO}_{2}$ emissions rather than atmospheric $\mathrm{CO}_{2}$ concentrations.

Several Representative Concentration Pathways (RCPs) have been formulated describing different trajectories of greenhouse gas emissions, air pollutant production, and land use changes for the 21 st century. These scenarios have been designed based on projections of human population growth, technological advancement, and societal responses (van Vuuren et al., 2011; Taylor et al., 2012). We analyzed simulations forced with specified concentrations of a high emissions scenario (RCP8.5) and a medium mitigation scenario (RCP4.5) reaching a radiative forcing level of 8.5 and $4.5 \mathrm{~W} \mathrm{~m}^{-2}$ at the end of the century, respectively. These simulations were initialized with the final state at the end of the historical runs and spanned the period 2006 to 2100.

The $1 \mathrm{pctCO} 2$ simulation is an idealized fully coupled carbon-climate simulation initialized from a steady state of the preindustrial control run and atmospheric $\mathrm{CO}_{2}$ concentration prescribed to increase $1 \% \mathrm{yr}^{-1}$ until a quadrupling of the preindustrial level. The simulations esmFixClim and esmFdbk aim to disentangle the two carbon cycle feedbacks 
(a)

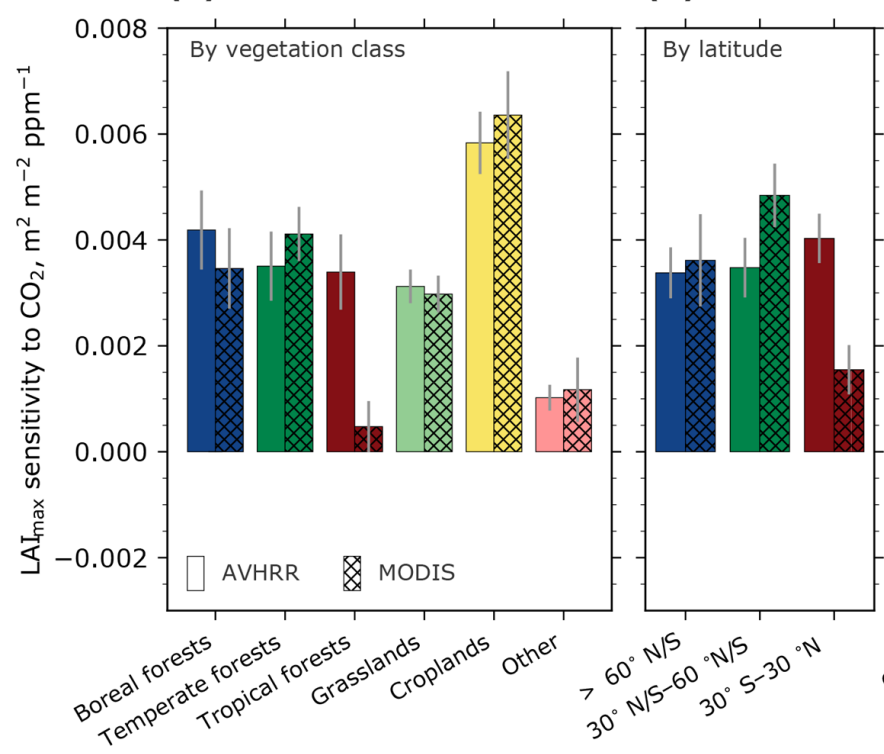

(c)

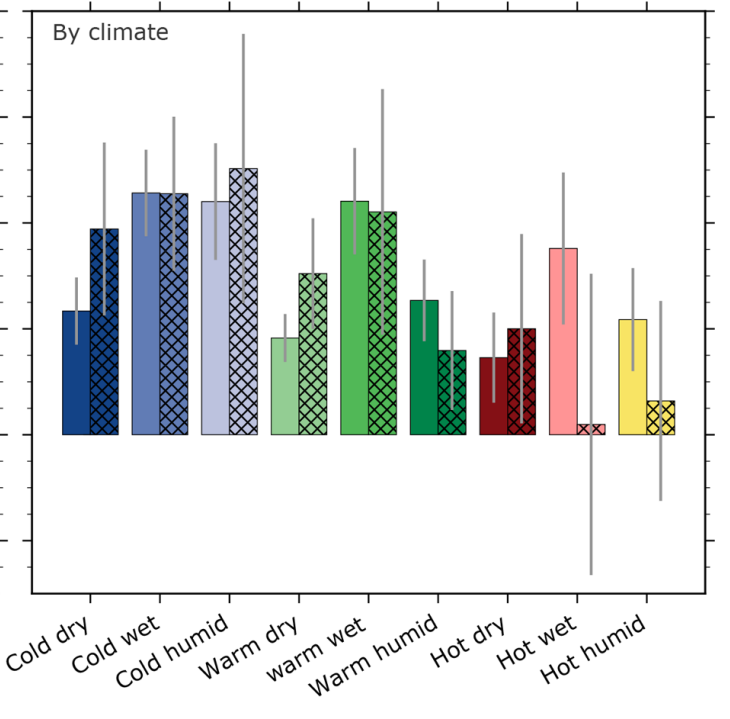

Figure 2. Bar charts showing regression slopes of $\mathrm{LAI}_{\max }$ against atmospheric $\mathrm{CO}_{2}$ concentration for broad vegetation classes (a) (Olson et al., 2001; Fritz et al., 2015), latitudinal bands (b), and climate regimes (c). The class "Other" includes deserts, mangroves, barren and urban land, snow and ice, and permanent wetlands. The climatic boundaries are defined as follows: cold: $<10^{\circ} \mathrm{C}$; warm: $>10$ and $<25^{\circ} \mathrm{C}$; hot: $>25^{\circ} \mathrm{C}$; dry: $<500 \mathrm{~mm} \mathrm{a}^{-1}$; wet: $>500$ and $<1000 \mathrm{~mm} \mathrm{a}^{-1}$; humid: $>1000 \mathrm{~mm} \mathrm{a}^{-1}$. Sensitivities evaluated from data from two satellite-borne sensors are shown, AVHRR (1982-2016; Pinzon and Tucker, 2014) and MODIS (2000-2016; Yan et al., 2016a, b). Gray bars indicate the standard error of the best linear fit.

in response to rising $\mathrm{CO}_{2}$ analogous to the $1 \mathrm{pctCO} 2$ setup. In esmFixClim $\mathrm{CO}_{2}$-induced climate change is suppressed (i.e., the radiation transfer model has a constant preindustrial $\mathrm{CO}_{2}$ level), while the carbon cycle responds to increasing $\mathrm{CO}_{2}$ concentration (vice versa for esmFdbk; Taylor et al., 2012; Arora et al., 2013).

\subsection{Estimation of greening sensitivities}

We largely follow the methodology detailed in Winkler et al. (2019). For both model and observational data, the twodimensional global fields of LAI and the driver variables are cropped according to different classification schemes (namely climatic regimes, latitudinal bands, and vegetation classes; Olson et al., 2001; Fritz et al., 2015). The aggregated values are area-weighted, averaged in space, and temporally reduced to annual estimates dependent on the variable: annual maximum LAI, annual average atmospheric $\mathrm{CO}_{2}$ concentration, and growing degree days (GDD0, yearly accumulated temperature of days with near-surface air temperature $>0{ }^{\circ} \mathrm{C}$ ).

We use a standard linear regression model to derive the historical greening sensitivities in models and observations alike (for details see the Methods section entitled "Estimation of historical LAI $\mathrm{max}_{\max }$ sensitivity" in Winkler et al., 2019). On the global scale, $\mathrm{LAI}_{\max }$ is assumed to be a linear function of atmospheric $\mathrm{CO}_{2}$ concentration. For the temperaturelimited high northern latitudes, we also have to account for warming and include temperature as an additional driver. We do this using GDD0. Through a principal component analysis (PCA) of $\mathrm{CO}_{2}$ and GDD0 we avoid redundancy from colinearity between the two driver variables but retain their underlying time trend and interannual variability (for details see the Methods section entitled "Dimension reduction using principal component analysis" in Winkler et al., 2019). In particular, the PCA is performed on large-scale aggregated values as well as on a pixel level to investigate spatial variations. We only retain the first principal component (denoted $\omega$ ), which explains a large fraction of the variance in models and observations (for more details see Table 1 in the Supplement in Winkler et al., 2019). Figure A1 depicts the temporal development of $\mathrm{CO}_{2}$ and GDD0 as well as their principal component $\omega$ for observations. For the NHLs, LAI $I_{\max }$ is then formulated as a linear function of the proxy driver time series $\omega$ (Winkler et al., 2019). The best-fit gradients and associated standard errors of the linear regression model represent the $\mathrm{LAI}_{\max }$ sensitivities, or greening sensitivities, and their uncertainty estimates, respectively.

\section{Results and discussion}

There are two parts to the EC methodology (Fig. 1) - a statistically robust relationship between modeled matching pairs of predictor-predictand values and an observed value of the predictor. The predictors are from a representative historical period. The predictands are modeled changes in a variable 
of interest at another forcing state of the system (e.g., potential future). The projection of the observed predictor on the modeled relation yields a constrained value of the predictand. A causal basis has to buttress the predictor-predictand relationship or the EC method may be spurious. For example, a meaningful coupling between concurrent changes in GPP and $\mathrm{LAI}_{\max }$ with an increasing atmospheric $\mathrm{CO}_{2}$ concentration underpins our specific case study in the NHLs; i.e., some of the enhanced GPP due to the rising $\mathrm{CO}_{2}$ concentration is invested in additional green leaves by plants (Myneni et al., 1997a; Forkel et al., 2016; Zhu et al., 2016; Mao et al., 2016; Winkler et al., 2019). Figure 1 of the Supplement in Winkler et al. (2019) illustrates the specifics of the causal link underlying this predictor-predictand relationship. This tight coupling ensures an approximately constant ratio of predictand to predictor across the models within the ensemble, thus setting up the potential for deriving an EC estimate. Uncertainty in the constrained estimate depends on the observed predictor and modeled relationship, aside from the goodness of fit of the latter (Fig. 1). These are detailed below.

\subsection{Uncertainty in observed predictor due to data source}

We investigate observational uncertainty using LAI data from two different sources, AVHRR $\left(1 / 12^{\circ}\right)$ and MODIS $\left(1 / 20^{\circ}\right)$, and spatially aggregating these over broad vegetation classes, latitudinal bands, and climatic regimes. The observed large-scale $\mathrm{LAI}_{\max }$ sensitivities to $\mathrm{CO}_{2}$ forcing are always positive (greening) irrespective of the source data and the method of aggregation (Fig. 2, Table 1). Overall, MODIS-based estimates have higher uncertainty because of the shorter length of the data record (17 years). The failure to reliably estimate sensitivities in tropical forests (also in the latitudinal band $30^{\circ} \mathrm{S}-30^{\circ} \mathrm{N}$ and in hot, wet, and humid climatic regimes; see Table 1 and Fig. 2) is due to the saturation of optical remote sensing data over dense vegetation $\left(\mathrm{LAI}_{\max }>5\right)$ and problems associated with high aerosol content and ubiquitous cloudiness. In other regions, the estimated sensitivities are comparable across sensors and aggregation schemes, in particular in the high-latitudinal band (>60 $\mathrm{N}-\mathrm{S}$; AVHRR: $(3.4 \pm 0.5) \times 10^{-3}$, MODIS: $(3.6 \pm$ $\left.0.9) \times 10^{-3} \mathrm{~m}^{2} \mathrm{~m}^{-2} \mathrm{ppm}^{-1} \mathrm{CO}_{2}\right)$. This aligns with previous studies reporting a net increase in green leaf area across the high latitudes during the observational period (Myneni et al., 1997b; Zhu et al., 2016; Forkel et al., 2016).

This analysis illustrates the applicability and limitations of using observed greening sensitivities to $\mathrm{CO}_{2}$ forcing as a constraint on photosynthetic production. For example, data from both AVHRR and MODIS sensors provide a comparable estimate of greening sensitivity in the colder high latitudes (boreal forests and tundra vegetation classes; Winkler et al., 2019). In the lower latitudes, however, the discrepancies among the two sensors indicate a considerable observa-
Table 1. Coefficients of determination $\left(R^{2}\right)$ of $\mathrm{LAI}_{\max }$ sensitivity to $\mathrm{CO}_{2}$ for different large-scale aggregated regions. Data are from two optical remote sensors of different time length, AVHRR (19822016) and MODIS (2000-2016). Asterisks denote nonsignificant values: ${ }^{* *} p>0.1{ }^{*} p>0.05$.

\begin{tabular}{lll}
\hline Correlation coefficient $R^{2}$ & AVHRR & MODIS \\
\hline Biomes & & \\
\hline Boreal forests & 0.49 & 0.58 \\
Temperate forests & 0.47 & 0.81 \\
Tropical forests & 0.41 & $0.06^{* *}$ \\
Grasslands & 0.75 & 0.83 \\
Croplands & 0.75 & 0.8 \\
Other & 0.35 & $0.2^{*}$ \\
\hline Latitudinal bands & & \\
\hline >60 N-S & & \\
$30-60^{\circ} \mathrm{N}-\mathrm{S}$ & 0.51 & 0.61 \\
$30^{\circ} \mathrm{S}-30^{\circ} \mathrm{N}$ & 0.67 & 0.83 \\
\hline Climate space & 0.65 & 0.26 \\
\hline Cold dry & & \\
Cold wet & & 0.27 \\
Cold humid & 0.29 & 0.4 \\
Warm dry & 0.49 & $0.21^{*}$ \\
Warm wet & 0.33 & 0.36 \\
Warm humid & 0.33 & $0.18^{*}$ \\
Hot dry & 0.37 & $0.12^{* *}$ \\
Hot wet & 0.25 & $0.08^{* *}$ \\
Hot humid & $0.08^{*}$ & $0.00^{* *}$ \\
\hline & 0.15 & $0.01^{* *}$ \\
\hline
\end{tabular}

tional uncertainty and thus no robust estimation of the observed predictor is possible.

\subsection{Uncertainty due to spatial aggregation}

We focus further analyses on the NHL region $\left(>60^{\circ} \mathrm{N}\right.$; Fig. 2b) for two reasons. First, the direct human impact (i.e., land management) can be neglected in the high latitudes, and thus we can assume that the observed changes reflect the response of natural ecosystems. Second, the observational evidence of increased plant productivity in recent decades is well established (e.g., Sect. 3.1; Keeling et al., 1996; Myneni et al., 1997a; Graven et al., 2013; Forkel et al., 2016; Wenzel et al., 2016) - an important requisite in defining a robust predictor.

In addition to the physiological effect of $\mathrm{CO}_{2}$, warming also plays a key role in controlling plant productivity in NHL temperature-limited ecosystems and thus vegetation greenness. To avoid redundancy from colinearity between $\mathrm{CO}_{2}$ and GDD0, we reduce dimensionality by performing a principal component analysis of the two driver variables (Sect. 2.4). The resulting first principal component explains most of the variance and retains the trend and year-to-year fluctuations 
in both $\mathrm{CO}_{2}$ and GDD0. Therefore, we obtain a proxy driver (hereafter denoted $\omega$ ) that represents the overall forcing signal causing observed vegetation greenness changes in NHLs (Fig. A1). Accordingly, greening sensitivity for the entire NHL area is derived as a response to $\omega$, the combined forcing signal of rising $\mathrm{CO}_{2}$ and warming. This procedure also enables better comparability between observations and models because varying strengths of the physiological and radiative effects of $\mathrm{CO}_{2}$ among models are taken into account (Sect. 3.3-3.5).

The vegetated landscape in the NHL region is heterogeneous, with boreal forests in the south, vast tundra grasslands to the north, and shrublands in between. The species within each of these broad vegetation classes respond differently to changes in key environmental factors. Even within a species, such responses might vary due to different boundary conditions, such as topography, soil fertility, and micrometeorological conditions. How this fine-scale variation in greening sensitivity impacts the aggregated value is assessed below.

The distribution of greening sensitivities from all NHL pixels is slightly skewed towards the positive (blue histogram). The mean value of this distribution (blue dashed line) is comparable to the sensitivity estimate derived from the spatially averaged NHL time series (dashed yellow line; Fig. 3). Based on the Mann-Kendall test ( $p>0.1)$, over half of the pixels $(54 \%)$ show positive statistically significant trends (greening), while about $10 \%$ show browning trends (possibly due to disturbances; Goetz et al., 2005). The distribution of these statistically significant sensitivities (red histogram) therefore has two modes, a weak browning and a dominant greening mode, resulting in a substantially higher mean value (red dashed line) in comparison to the spatially averaged estimate (dashed yellow line; Fig. 3). Thus, by taking into account the remaining $36 \%$ of nonsignificantly changing pixels (as in the NHL spatially averaged estimate), an additional source of uncertainty is possibly introduced. The mean sensitivity value is, of course, higher when only pixels showing a greening trend are considered in the analysis (green dashed line; Fig. 3). These are the only areas in NHLs that actually show a large increase in plant productivity and consequently significant changes in leaf area.

The model output of several ESMs (CMIP5) reveal similar pixel-level variation in both the predictor $\left(\mathrm{LAI}_{\max }\right.$ to $\omega$, historical simulation; Sect. 2.3) and associated changes in the predictand (GPP, 1pctCO2; Sect. 2.3), although ESMs operate on much coarser resolution (Fig. A2; see also Anav et al., 2013, 2015). Due to the coupling of the predictor and predictand, the distribution of pixels with significant changes is approximately the same for the two variables (Fig. A2). Accordingly, averaging the equally distributed estimates likely does not affect the predictor-predictand relationship in the model ensemble (Fig. 1). Consequently, if all spatial gridded data arrays are consistently processed to spatially aggregated estimates, each predictand and predictor (observed and modeled) estimate contains a coherent component of spatial vari-

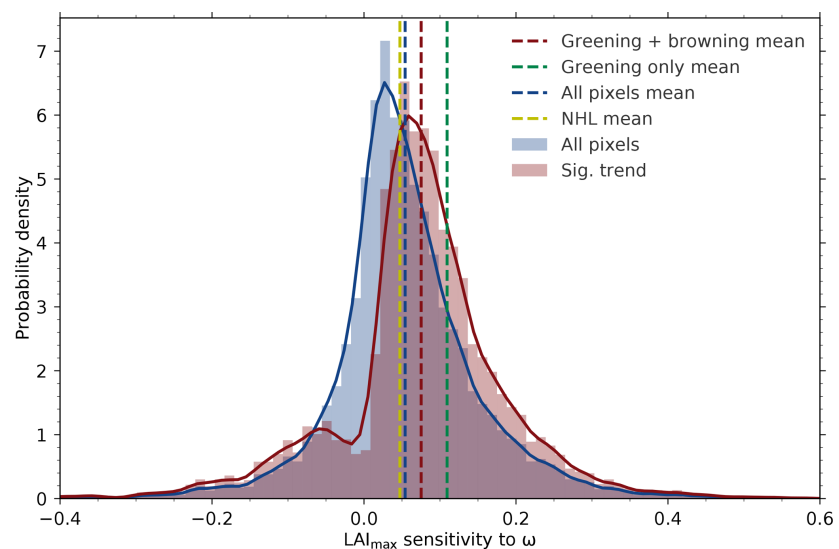

Figure 3. Histograms and associated probability density functions (Gaussian kernel density estimation) of observed LAI $\mathrm{Lax}_{\text {max }}$ sensitivity to $\omega$ at pixel scale for the northern high-latitudinal band ( $>60^{\circ} \mathrm{N}$, data from AVHRR sensor). Blue depicts the distribution of LAI $\mathrm{I}_{\max }$ sensitivities of all pixels and red is for pixels with statistically significant (Mann-Kendall test, $p<0.1$ ) greening or browning trends (the dashed lines denote the respective mean value). The green dashed line shows the mean value of "greening" pixels only, whereas the dashed yellow line shows the $\mathrm{LAI}_{\max }$ sensitivity to $\omega$ for the entire northern high-latitudinal belt.

ations. In other words, considering browning and nonsignificant pixels results in a lower overall $\mathrm{LAI}_{\max }$ sensitivity in NHLs, which in turn leads to a lower constrained estimate of $\Delta$ GPP in NHLs. This is consistent with the underlying relationship between the predictor and predictand. On a related note, Bracegirdle and Stephenson (2012a) suggest that this source of error is not significantly dependent on the spatial resolution when comparing model subsets from high to low resolution.

The above analysis confirms that spatially averaged estimates are approximations containing a random error component due to the inclusion of data from insignificantly changing pixels and a systematic bias component from pixels of reversed sign. This uncertainty is relevant to the EC method, wherein the observed sensitivity decisively determines the constrained estimate from the ensemble of ESM projections (Kwiatkowski et al., 2017; Winkler et al., 2019). However, if spatial variations are treated consistently as an inherent component of observations and models, the EC method is only slightly susceptible to this source of uncertainty.

\subsection{Uncertainty due to temporal variations}

We rely on long-term CMIP5 ESM simulations covering the historical period 1850 to 2005 (Sect. 2.3) to assess the temporal variation in the predictor variable because of the shortness of the observational record. Three representative models (CESM1-BGC, MIROC-ESM, and HadGEM2-ES) spanning the full range of NHL greening sensitivities in the CMIP5 ensemble (Winkler et al., 2019) are selected for this analysis. 


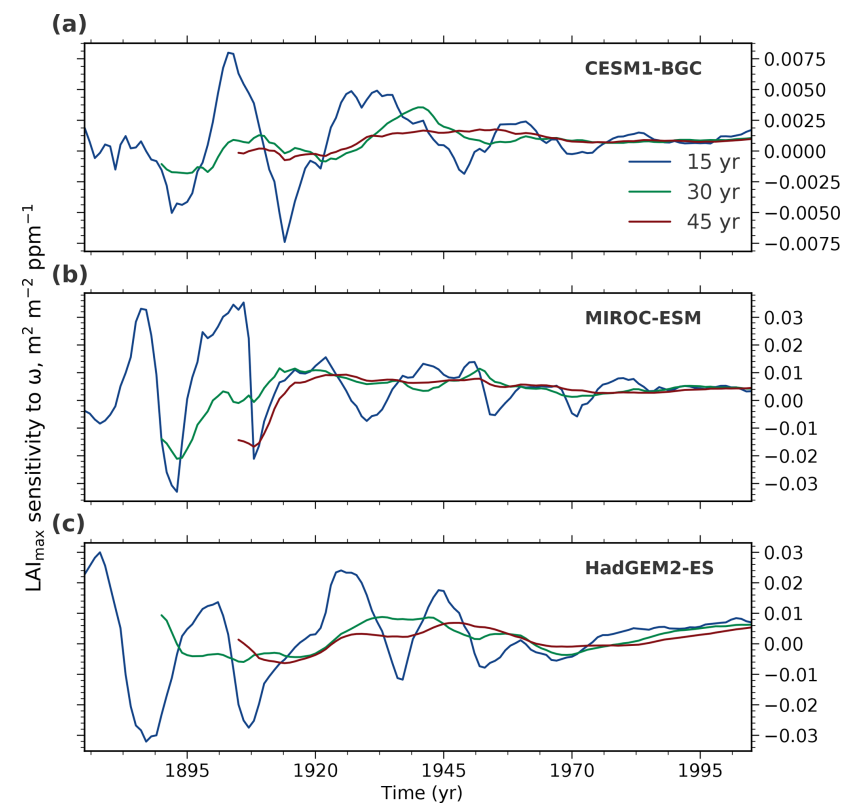

Figure 4. Temporal variation of $\mathrm{LAI}_{\max }$ sensitivity to $\omega$ in three selected CMIP5 models spanning the full range from low-end (CESM1-BGC, a), to closest to observations (MIROC-ESM, b), to high-end (HadGEM2-ES, c). The colored lines show LAI $I_{\max }$ sensitivity variations for moving windows of varying length: 15 (blue), 30 (green), and 45 (red) years over the historical period from 1860 to 2005 .

For each model, $\mathrm{LAI}_{\max }$ sensitivity to $\omega$ in moving windows of different lengths is evaluated $(15,30$, and 45 years; Figs. 4 and A3). The analysis reveals two crucial aspects that highlight how temporal variations impair the comparability of the predictor variable between models and observations - an essential component of the EC approach.

First, the window locations of modeled and observed predictor variables have to match. If the forcing in the simulations is low, for example in the second half of the 19th century when the $\mathrm{CO}_{2}$ concentration was increasing slowly, interannual variability dominates and $\mathrm{LAI}_{\max }$ sensitivity cannot be accurately estimated irrespective of the window length (Figs. 4 and A3). With increasing forcing over time (rising yearly rate of $\mathrm{CO}_{2}$ emissions and, consequently, the concentration), the signal-to-noise ratio increases and $\mathrm{LAI}_{\max }$ sensitivity to $\omega$ estimation stabilizes, for example in the second half of the 20th century. Therefore, $\mathrm{LAI}_{\max }$ sensitivities estimated at different temporal locations result in noncomparable values and eventually a false constrained estimate (details in Sect. 3.4). As an example, modeled sensitivities based on a 30-year window centered on the year 1900 , when the $\mathrm{CO}_{2}$ level increased by $10 \mathrm{ppm}$, and observed sensitivity estimated from a 30-year window centered on the year 2000, when the $\mathrm{CO}_{2}$ level increased by $55 \mathrm{ppm}$, describe different states of the system and therefore should not be contrasted in the EC method.
Second, in addition to the temporal location, window lengths also have to match between observations and models. For all three models, sensitivities estimated from 15-year chunks show high variability, and thus a 15 -year record is perhaps too short to obtain robust estimates. The $\mathrm{LAI}_{\max }$ sensitivity estimation becomes more stable with strengthening forcing and increasing window length (Figs. 4 and A3). As a consequence, using short-term observed sensitivity as a constraint on long-term model projections results in an incorrect EC estimate. Hence, the MODIS sensor record is, on the one hand, too short and does not, on the other hand, overlap temporally with the historical CMIP5 forcing. Therefore, it does not provide a robust predictor in this EC study.

\subsection{Level and time rate of $\mathrm{CO}_{2}$ forcing}

The EC method raises an obvious question - does it not implicitly assume that the key operative mechanisms underpinning the EC relation remain unchanged because a future system state is being predicted based on its past behavior? To be specific, we are attempting to predict GPP at a future point in time based on greening sensitivity inferred from the past. Does this not require the assumption that the key underlying relationship that makes this prediction possible, namely a robust coupling between contemporaneous changes in GPP and $\mathrm{LAI}_{\max }$, remains unchanged from the past to the future? To address this question, we resort to the CMIP5 idealized simulation (1pctCO2), wherein atmospheric $\mathrm{CO}_{2}$ concentration increases $1 \%$ annually, starting from a preindustrial level of $284 \mathrm{ppm}$ until a quadruple of this value is reached (Sect. 2.3). We limit the analysis to the three models (CESM1-BGC, MIROC-ESM, and HadGEM2-ES) that bracket the full range of GPP enhancement and $\mathrm{LAI}_{\max }$ sensitivity in the original seven-ESM ensemble (Winkler et al., 2019).

The relationship between simultaneous changes in GPP and $\mathrm{LAI}_{\max }$ remains linear for all CMIP5 models in the range $1 \times \mathrm{CO}_{2}$ to $2 \times \mathrm{CO}_{2}$ (Figs. 5 and A4, Table 2). With concentration increasing beyond $2 \times \mathrm{CO}_{2}$, all models show a weakening correlation $\left(R^{2}\right.$; Table 2$)$ and decreasing slope $(b$; Table 2) of this relationship (Figs. 5 and A4), suggesting a saturating rate of allocation of additional GPP to new leaves at higher levels of $\mathrm{CO}_{2}$. Consequently, $\mathrm{LAI}_{\max }$ sensitivity to increasing $\mathrm{CO}_{2}$ and associated warming decreases. At and over $4 \times \mathrm{CO}_{2}(1140 \mathrm{ppm})$, a level unlikely to be seen in the near future, there appears to be no relationship between $\Delta$ GPP and $\Delta \mathrm{LAI}_{\max }$ in some models. This raises the question of to what extent the weakening of the relationship between the predictor and predictand in each model at higher $\mathrm{CO}_{2}$ concentrations affects the EC analysis (Fig. 1). To shed light on this matter, we perform the following thought experiment.

Understanding the relationship and interplay between forcing (increasing $\mathrm{CO}_{2}$ concentration), the predictor ( $\mathrm{LAI}_{\max }$ sensitivity), and the predictand $(\triangle \mathrm{GPP})$ is key to evaluating the EC method. We conceive four possible scenarios of how the system might behave with increasing forc- 
Table 2. Slopes $(b)$ and coefficients of determination $\left(R^{2}\right)$ for regression between changes in $\mathrm{LAI}_{\max }$ against changes in annual mean GPP for the NHLs at different atmospheric $\mathrm{CO}_{2}$ levels in all available CMIP5 models (1pctCO2 simulation). Asterisks denote nonsignificant values: ${ }^{* *} p>0.1 ;{ }^{*} p>0.05$.

\begin{tabular}{|c|c|c|c|c|c|c|}
\hline \multirow[t]{2}{*}{ Correlation details } & \multicolumn{4}{|c|}{$>2 \times \mathrm{CO}_{2} \&$} & \multicolumn{2}{|c|}{$>3 \times \mathrm{CO}_{2}$} \\
\hline & $b$ & $R^{2}$ & $b$ & $R^{2}$ & $b$ & $R^{2}$ \\
\hline MIROC-ESM & 0.23 & 0.97 & 0.16 & 0.89 & 0.08 & 0.63 \\
\hline CESM1-BGC & 0.45 & 0.93 & 0.36 & 0.82 & 0.27 & 0.62 \\
\hline GFDL-ESM2M & 0.37 & 0.89 & 0.04 & $0.07^{* *}$ & 0.01 & $0.12^{* *}$ \\
\hline CanESM2 & 0.22 & 0.95 & 0.19 & 0.83 & 0.17 & 0.67 \\
\hline HadGEM2-ES & 0.13 & 0.99 & 0.08 & 0.96 & 0.06 & 0.78 \\
\hline MPI-ESM-LR & 0.13 & 0.94 & 0.09 & 0.78 & 0.04 & 0.51 \\
\hline NorESM1-ME & 0.26 & 0.94 & 0.2 & 0.77 & 0.09 & 0.27 \\
\hline
\end{tabular}

ing. For simplicity, we assume a linearly increasing $\mathrm{CO}_{2}$ concentration; LAI represents $\mathrm{LAI}_{\max }$, and GPP refers to its annual value below (Fig. 6). The four scenarios are as follows: all linear, all nonlinear (saturation), and two mixed linearnonlinear cases (Table A1). We emulate a multi-model ensemble by applying different random parameterizations for the linear and saturation (the hyperbolic tangent function) responses of GPP to $\mathrm{CO}_{2}$ and of LAI to GPP. One of these realizations is assumed to represent pseudo observations (dashed lines, Fig. 6). We discuss one case in detail for illustrative purposes (no. 3; Table A1).

In scenario $3, \triangle \mathrm{GPP}$ increases linearly with increasing $\mathrm{CO}_{2}$ (Fig. 6a), while $\Delta \mathrm{LAI} / \Delta$ GPP saturates (Fig. 6b). The LAI sensitivity to $\mathrm{CO}_{2}$ weakens with increasing forcing (Fig. 6c) as a response to the saturation of GPP allocation to leaf area. We derive LAI sensitivities to $\mathrm{CO}_{2}$ for three different periods ("past periods" in Fig. 6c) to constrain $\triangle \mathrm{GPP}$ at a much higher $\mathrm{CO}_{2}$ level ("projected period" in Fig. 6a). Next, we apply the EC method on these pseudo projections of $\triangle \mathrm{GPP}$, relying on LAI sensitivities derived from the three past periods (Fig. 6d). The EC method is applicable even at a low forcing level (past period 1) in this simplified scenario because we neglect the stochastic internal variability of the system. The slope of the emergent linear relationship increases (Fig. 6d) as modeled LAI sensitivities decrease with a rising $\mathrm{CO}_{2}$ concentration (Fig. 6c). The observational constraint on future $\triangle \mathrm{GPP}$, however, remains nearly the same because pseudo-observed LAI sensitivity also weakens at higher $\mathrm{CO}_{2}$ levels (dashed lines, Fig. 6c and d). Thus, the three EC estimates of $\triangle$ GPP are approximately identical (Fig. 6d) and independent of the forcing level during past periods. With intensified forcing, the relationship between the predictor and predictand remains linear within the model ensemble, although their relationship becomes nonlinear within each model and, crucially, in reality as well. In other words, as long as the models agree on the occurrence and strength of saturation for given forcing, i.e., the dynamics of the system, the inter-model variations of the predictor and predictand re- late linearly within the ensemble (Fig. 6). The same behavior is also seen in the other three scenarios (Table A1; Figs. A5 and A6).

Nevertheless, with ever increasing forcing and associated steepening of the emergent linear relationship, the LAI sensitivity loses its explanatory power at some point because the linear relationship eventually lies within the observational uncertainty and no meaningful constraint can be derived. This and disagreement between models on system dynamics are ultimate limits of the EC method. Interestingly, we find that all CMIP5 models agree on the occurrence of saturation but slightly disagree on the strength of saturation for given $\mathrm{CO}_{2}$ forcing (Figs. 5 and A4, and Table 2). Further, we find that the "all nonlinear" scenario best describes the dynamics of the system in the forcing range from $1 \times \mathrm{CO}_{2}$ to $4 \times \mathrm{CO}_{2}$. However, the saturation of LAI to GPP happens at a lower $\mathrm{CO}_{2}$ level than saturation of GPP to $\mathrm{CO}_{2}$. Still, inferences from the interpretation of Case 3 (Fig. 6) are equally applicable.

Results from the above thought experiment also highlight the importance of matching window locations and lengths between models and observations, as discussed earlier (Sect. 3.3). For instance, taking LAI sensitivity from past period 2 (green dashed line, Fig. 6d) as an observational constraint on the multi-model linear relationship based on past period 3 (red solid line, Fig. 6d) results in a significant overestimation of constrained $\triangle \mathrm{GPP}$ (intersection of the two lines, Fig. 6d).

The above analysis confirms that the constrained GPP estimate at one future period (e.g., $2 \times \mathrm{CO}_{2}$ ) is nearly independent of the past periods from which the observational sensitivities are derived. Now, we evaluate the EC method wherein the sensitivity from one past period is used to obtain constrained GPP estimates at different periods in a potential future, i.e., progressively farther down the timeline of a $\mathrm{CO}_{2}$ enriched world. We utilize the greening sensitivity derived from 35 years of observed $\mathrm{LAI}_{\max }$ data (AVHRR; Sect. 2.1) and apply the EC method to CMIP5 1pctCO2 simulations. 


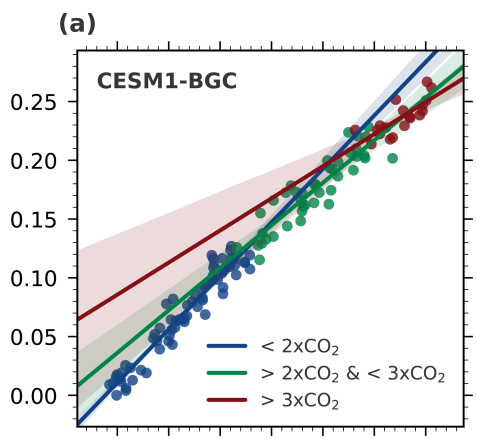

$\begin{array}{lllllll}0.0 & 0.1 & 0.2 & 0.3 & 0.4 & 0.5 & 0.6\end{array}$

(b)

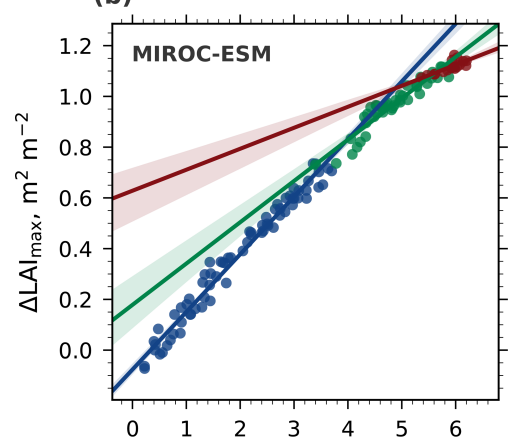

(c)

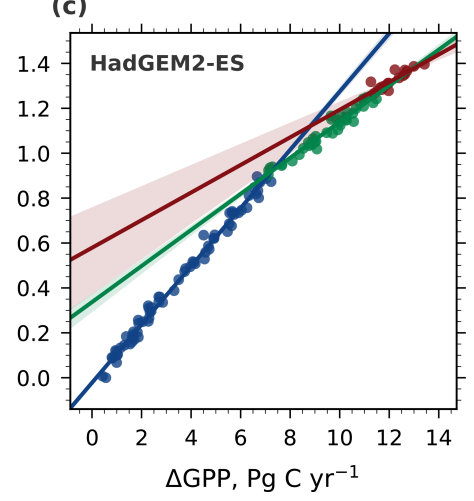

Figure 5. Correlation of $\Delta \mathrm{LAI}_{\max }$ and $\Delta \mathrm{GPP}$ with increasing $\mathrm{CO}_{2}$ forcing, starting from a preindustrial concentration of $280 \mathrm{ppm}(1 \times$ $\mathrm{CO}_{2}$ ) to $4 \times \mathrm{CO}_{2}$ (CMIP5 1 pctCO2 simulations). Results are shown for three selected CMIP5 models spanning the full range of $\mathrm{LAI}_{\max }$ sensitivity to $\omega$ : low-end: CESM1-BGC (a), closest to observations: MIROC-ESM (b), and high-end: HadGEM2-ES (c). Blue colored dots show the relation between $1 \times \mathrm{CO}_{2}$ and $2 \times \mathrm{CO}_{2}$, green colored dots between $2 \times \mathrm{CO}_{2}$ and $3 \times \mathrm{CO}_{2}$, and red colored dots between $3 \times \mathrm{CO}_{2}$ and $4 \times \mathrm{CO}_{2}$. The respective colored lines represent the best linear fit through those dots and the shading represents the $95 \%$ confidence interval.

The sensitivities in this case are due to forcing from both the $\mathrm{CO}_{2}$ increase and associated warming during the observational period (Sect. 2.4). We seek constrained GPP estimates for the NHLs at different $\mathrm{CO}_{2}$ levels $\left(2 \times \mathrm{CO}_{2}, 3 \times \mathrm{CO}_{2}\right.$, and $4 \times \mathrm{CO}_{2}$ ).

Winkler et al. (2019) previously reported a strong linear relationship between modeled contemporaneous changes in
$\mathrm{LAI}_{\max }$ and GPP arising from the combined radiative and physiological effects of $\mathrm{CO}_{2}$ enrichment until $2 \times \mathrm{CO}_{2}$ in the CMIP5 ensemble. As a result, models with low LAI $\mathrm{max}_{\max }$ sensitivity to $\omega$ project lower $\Delta$ GPP for a given increment of $\mathrm{CO}_{2}$ concentration and vice versa. Thus, the large variation in modeled historical $\mathrm{LAI}_{\max }$ sensitivities linearly maps to the variation in $\triangle \mathrm{GPP}$ at $2 \times \mathrm{CO}_{2}$ (blue line, Fig. $7 \mathrm{a}$; Winkler et al., 2019). At higher levels, such as $3 \times \mathrm{CO}_{2}$ (green line, $R^{2}=0.93$ ) and $4 \times \mathrm{CO}_{2}$ (red line, $R^{2}=0.88$ ), this linear relationship within the model ensemble, while still present, weakens (Fig. 7a; Table 3). This is because the CMIP5 models do not agree on the strength of the saturation effect at higher $\mathrm{CO}_{2}$ levels (Figs. 5 and A4). The increment in constrained GPP estimates for successive equal increments of $\mathrm{CO}_{2}$ decreases due to the saturation effect in all CMIP5 models (dashed horizontal lines, Fig. 7a). For example, the change in GPP between $3 \times \mathrm{CO}_{2}$ and $4 \times \mathrm{CO}_{2}$ $\left(\triangle \mathrm{GPP} \sim 1.06 \mathrm{Pg} \mathrm{Cyr}^{-1}\right.$; Table 3$)$ is much lower than between $2 \times \mathrm{CO}_{2}$ and $3 \times \mathrm{CO}_{2}\left(\Delta \mathrm{GPP} \sim 2.34 \mathrm{Pg} \mathrm{Cyr}^{-1}\right.$; Table 3).

We have thus far focused on the magnitude of $\mathrm{CO}_{2}$ concentration change and not on the time rate of this change. For example, a given amount of change in $\mathrm{CO}_{2}$ concentration, say $200 \mathrm{ppm}$, can be realized over different time periods, say over 100 or 150 years. The problem of varying rates of $\mathrm{CO}_{2}$ concentration change is implicitly encountered when ESMs are executed under different forcing scenarios, such as RCPs (Sect. 2.3). A question then arises as to whether the constrained predictand estimate is independent of the time rate of $\mathrm{CO}_{2}$ concentration change and dependent only on the magnitude of $\mathrm{CO}_{2}$ concentration change. To investigate this aspect of forcing, we extract GPP estimates at the same $\mathrm{CO}_{2}$ concentration $(535 \mathrm{ppm}$; final concentration in RCP4.5) from three simulations of different forcing rates and calculate the difference relative to a common initial $\mathrm{CO}_{2}$ concentration $(380 \mathrm{ppm}$; initial concentration of RCP scenarios). Hence, the magnitude of the forcing is the same but applied over different durations (RCP4.5: $\sim 90$ years, RCP8.5: $\sim 45$ years, and 1 pctCO2: $\sim 30$ years). A clear majority of the CMIP5 models show substantial differences in $\triangle \mathrm{GPP}$ between the different pathways of $\mathrm{CO}_{2}$ forcing. In general, GPP changes are higher for lower time rates of $\mathrm{CO}_{2}$ forcing, i.e., forcing over longer time periods. As a consequence, the EC estimates of $\triangle \mathrm{GPP}$ for the same increase in $\mathrm{CO}_{2}$ concentration are scenario dependent (Fig. 7b; Table 3) - a counterintuitive result. For instance, in the RCP4.5 scenario (which is characterized by a lower rate of $\mathrm{CO}_{2}$ increase) an increment of $155 \mathrm{ppmCO}_{2}$ yields a GPP enhancement of $\sim 2.84 \mathrm{Pg} \mathrm{Cyr}^{-1}$ (see Table 3 ). This GPP enhancement is $\sim 39 \%$ and $\sim 20 \%$ larger than in the 1 pctCO2 run $\left(\sim 2.05 \mathrm{PgC} \mathrm{yr}^{-1}\right.$; Table 3$)$ and the RCP8.5 $\left(\sim 2.38 \mathrm{PgC} \mathrm{yr}^{-1}\right.$; Table 3$)$ scenario, respectively, for the same total increase in $\mathrm{CO}_{2}$ concentration. Both these scenarios are characterized by a faster rate of $\mathrm{CO}_{2}$ increase than RCP4.5. This analysis suggests that the vegetation response 
(a)

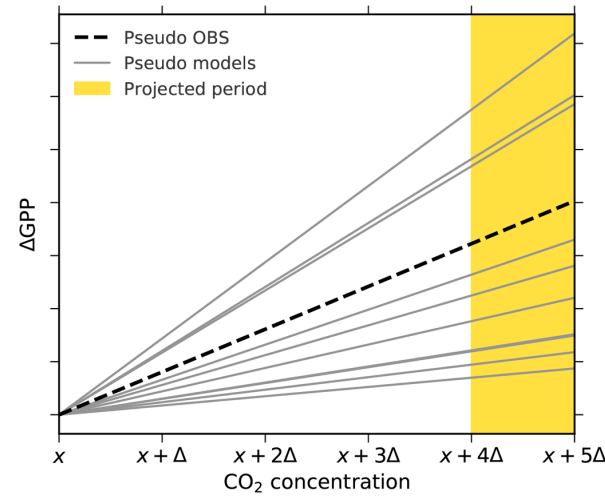

(c)

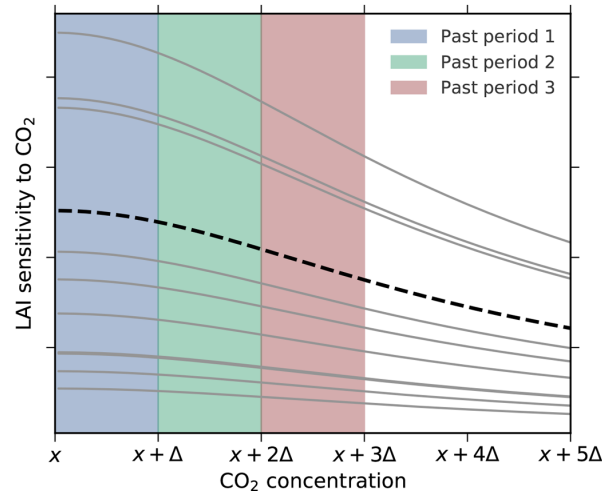

(b)

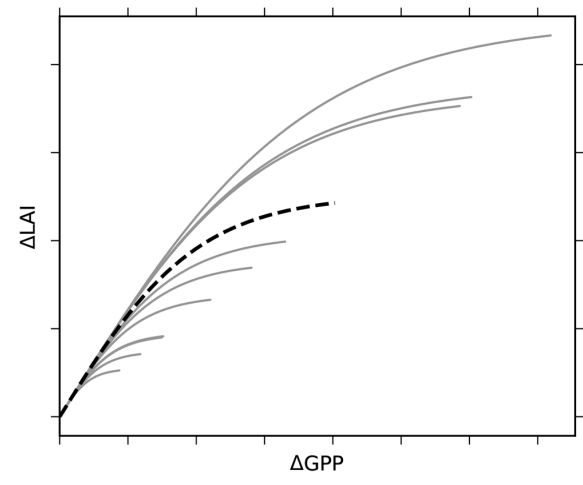

(d)

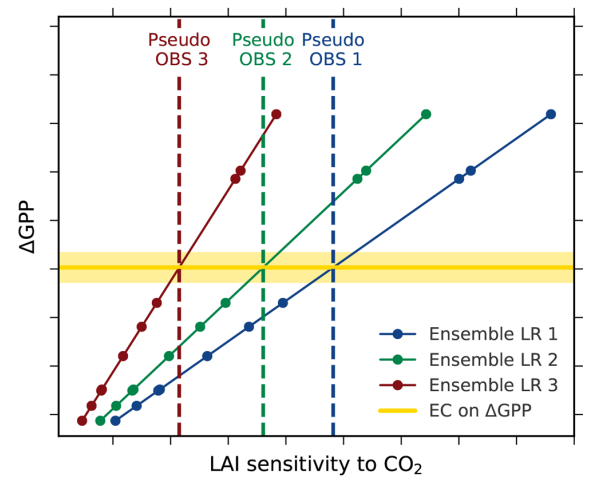

Figure 6. Thought experiment to examine the applicability of EC analysis under the assumption of an idealized linear-nonlinear behavior of the system (Case 3, Table A1). (a) Changes in GPP relate linearly to changes in $\mathrm{CO}_{2}$ concentration. The yellow band marks the projection period of interest, i.e., the period of $\mathrm{CO}_{2}$ concentration from $x+4 \Delta$ to $x+5 \Delta$. (b) The increment in LAI with increasing GPP is assumed to decrease with rising $\mathrm{CO}_{2}$ concentration (described by a hyperbolic tangent function). The parameterization in the linear and nonlinear functions for pseudo observations (dashed black line) as well as models (solid gray lines) is determined randomly for each model. (c) The diagnostic variable, LAI sensitivity to $\mathrm{CO}_{2}$, decreases with increasing $\mathrm{CO}_{2}$ as a consequence of the nonlinear relation between $\Delta \mathrm{GPP}$ and $\Delta$ LAI. The colored bands indicate three "past" periods from $x$ to $x+\Delta$ (blue), $x+\Delta$ to $x+2 \Delta$ (green), and $x+2 \Delta$ to $x+3 \Delta$ (red). (d) Linear relationships among the pseudo model ensembles (Ensemble LR, colored lines) between LAI sensitivities to $\mathrm{CO}_{2}$ of the three past periods and $\triangle$ GPP from the projected period. Colored dots mark different models and the dashed lines represent associated pseudo observations for the respective historical period. The solid yellow line depicts the constant EC on projected $\Delta \mathrm{GPP}$ irrespective of the past period.

to rising $\mathrm{CO}_{2}$ is pathway dependent, at least in the NHLs. One of the reasons for this could be species compositional changes in scenarios of low forcing rates, i.e., over longer time frames. This novel result, however, requires a separate in-depth study.

\subsection{Effects of $\mathrm{CO}_{2}$ forcing}

A higher concentration of $\mathrm{CO}_{2}$ in the atmosphere stimulates plant productivity through fertilization and radiative effects (Nemani et al., 2003; Leakey et al., 2009; Arora et al., 2011; Goll et al., 2017). The two effects can be disentangled in the model world by conducting simulations in a " $\mathrm{CO}_{2}$ fertilization effect only" (esmFixClim1) and a "radiative effect only" (esmFdbk1) setup (Sect. 2.3). These are termed below as idealized model simulations. We investigate here whether historical runs and observations, which include both effects, can be used to constrain GPP changes in idealized CMIP5 simulations (as in Wenzel et al., 2016).

We find strong linear relationships between historical $\mathrm{LAI}_{\max }$ sensitivity and $\triangle \mathrm{GPP}$ for $2 \times \mathrm{CO}_{2}$ in both idealized setups (esmFixClim1: $R^{2}=0.92$, esmFdbk1: $R^{2}=$ 0.98; Table 3, Fig. 7c). Consequently, this linear relationship is also pronounced for calculated sums of both effects for each model (esmFixClim1 + esmFdbk1: $R^{2}=0.95$; Table 3, Fig. 7c). This suggests that the two effects act additively on plant productivity, and thus each effect can be simply expressed in terms of a scaling factor of the total GPP enhancement. Hence, the application of the EC method on idealized simulations using real-world observations is conceptually feasible.

Interestingly, the two effects contribute about the same to the general increase in GPP at $2 \times \mathrm{CO}_{2}$ (esmFixClim1: $\quad \Delta \mathrm{GPP} \sim 1.35 \mathrm{PgC} \mathrm{yr}^{-1}, \quad$ esmFdbk1: 
Table 3. Coefficients of determination $\left(R^{2}\right)$ of the emergent linear relationships in Fig. 7 (asterisks denote nonsignificant values: ${ }^{* *} p>0.1$; $* p>0.05$ ). ECs on $\triangle$ GPP (upper and lower bound of uncertainty in square brackets) for different atmospheric $\mathrm{CO}_{2}$ levels and fully coupled as well as idealized setups. The rightmost column shows the increase in $\Delta \mathrm{GPP}$ for an increment of $1 \times \mathrm{CO}_{2}$. The lowermost section compares EC estimates of $\triangle \mathrm{GPP}$ for equivalent changes in $\mathrm{CO}_{2}$ concentration $\left(\mathrm{CO}_{2}\right.$ rises from 380 to $\left.535 \mathrm{ppm}\right)$ but for different time rates.

\begin{tabular}{|c|c|c|c|}
\hline & $R^{2}$ & $\begin{array}{r}\mathrm{EC} \Delta \mathrm{GPP} \\
\text { estimate } \\
\left(\mathrm{PgC} \mathrm{yr}^{-1}\right)\end{array}$ & $\begin{array}{c}\text { EC } \Delta \text { GPP for } \\
\Delta 1 \times \mathrm{CO}_{2} \\
\left(\mathrm{Pg} \mathrm{Cyr}^{-1}\right)\end{array}$ \\
\hline \multicolumn{4}{|l|}{$2 \times \mathrm{CO}_{2}$} \\
\hline Fully coupled (1pctCO2) & 0.96 & $3.36[3.15,3.56]$ & - \\
\hline $\mathrm{CO}_{2}$ fertilization only (esmFixClim1) & 0.88 & $1.35[1.29,1.62]$ & - \\
\hline Radiative effect only (esmFdbk1) & 0.94 & $1.38[1.13,1.51]$ & - \\
\hline Sum of both effects (esmFixClim1 + esmFdbk1) & 0.95 & $2.74[2.6,2.9]$ & - \\
\hline \multicolumn{4}{|l|}{$3 \times \mathrm{CO}_{2}$} \\
\hline Fully coupled (1pctCO2) & 0.93 & $5.7[5.26,6.16]$ & 2.34 \\
\hline $\mathrm{CO}_{2}$ fertilization only (esmFixClim1) & 0.92 & $2.15[2.02,2.37]$ & 0.79 \\
\hline Radiative effect only (esmFdbk1) & 0.98 & $2.53[2.3,2.66]$ & 1.15 \\
\hline Sum of both effects (esmFixClim1 + esmFdbk1) & 0.96 & $4.68[4.38,4.97]$ & 1.94 \\
\hline \multicolumn{4}{|l|}{$4 \times \mathrm{CO}_{2}$} \\
\hline Fully coupled (1pctCO2) & 0.88 & $6.76[6.08,7.53]$ & 1.06 \\
\hline $\mathrm{CO}_{2}$ fertilization only (esmFixClim1) & 0.88 & $2.42[2.23,2.74]$ & 0.28 \\
\hline Radiative effect only (esmFdbk1) & 0.97 & $3.06[2.83,3.2]$ & 0.53 \\
\hline Sum of both effects (esmFixClim $1+$ esmFdbk1) & 0.95 & $5.49[5.09,5.85]$ & 0.81 \\
\hline \multicolumn{4}{|l|}{$380-535 \mathrm{ppm} \mathrm{CO}_{2}$} \\
\hline Slow increase in $\mathrm{CO}_{2}(\mathrm{RCP} 4.5)$ & 0.93 & $2.84[2.54,3.08]$ & - \\
\hline Medium-fast increase in $\mathrm{CO}_{2}$ (RCP8.5) & 0.96 & $2.38[2.18,2.55]$ & - \\
\hline Rapid increase in $\mathrm{CO}_{2}(1 \mathrm{pctCO} 2)$ & 0.96 & $2.05[1.94,2.16]$ & - \\
\hline
\end{tabular}

$\Delta \mathrm{GPP} \sim 1.38 \mathrm{Pg} \mathrm{Cyr}^{-1}$; Table 3, Fig. 7c). At higher concentrations, such as $3 \times \mathrm{CO}_{2}$ and $4 \times \mathrm{CO}_{2}$, the enhancement in GPP saturates in both idealized setups. However, the radiative effect becomes dominant relative to the $\mathrm{CO}_{2}$ fertilization effect when $\mathrm{CO}_{2}$ concentration exceeds $2 \times \mathrm{CO}_{2}$ (e.g., at $4 \times \mathrm{CO}_{2}$ esmFixClim1: $\triangle \mathrm{GPP} \sim 2.42 \mathrm{Pg} \mathrm{Cyr}^{-1}$, esmFdbk1: $\triangle \mathrm{GPP} \sim 3.06 \mathrm{Pg} \mathrm{C} \mathrm{yr}^{-1}$; Table 3). Therefore, we can expect that at some point in the future, NHL photosynthetic carbon fixation will benefit more from climate change (e.g., warming) than from the fertilizing effect of $\mathrm{CO}_{2}$.

\subsection{Uncertainties in the multi-model ensemble}

Besides the methodological sources of uncertainty discussed above, the estimate of an EC may also be deficient due to inaccurate assumptions about the model ensemble. First, possible common systematic errors in a multi-model ensemble (i.e., the entire ensemble misses an unknown process that plays a key role in a high $\mathrm{CO}_{2}$ world) are implicitly omitted in the EC approach; however, they could cause a general overestimation or underestimation of the constrained value (Bracegirdle and Stephenson, 2012b; Stephenson et al., 2012). Second, the set of forcing variables for historical sim- ulations may be incomplete (i.e., not yet identified drivers of observed changes), and thus the comparability of observations and model simulations is limited (Flato et al., 2013). Third, the EC method can be overly sensitive to individual models of the ensemble, which has a bearing on the robustness of the constrained value (Bracegirdle and Stephenson, $2012 b)$. Bracegirdle and Stephenson (2012b) proposed a diagnostic metric (Cook's distance) to test an ensemble for influential models. Fourth, the predictand-predictor relationship not only has to rely on a physical but also on a logical connection within the model ensemble. For instance, Wenzel et al. (2016) established a linear relationship between relative changes in the predictand taking the initial state into account (changes in GPP for a doubling of $\mathrm{CO}_{2}$ relative to the initial preindustrial state) and a predictor neglecting the initial state (historical sensitivity of $\mathrm{CO}_{2}$ amplitude to rising $\mathrm{CO}_{2}$ ). This statistical relationship can be spurious because the model skills in simulating an accurate initial state and a plausible sensitivity to a forcing are not connected. These issues are to be contemplated when establishing an EC estimate and evaluating its robustness. 


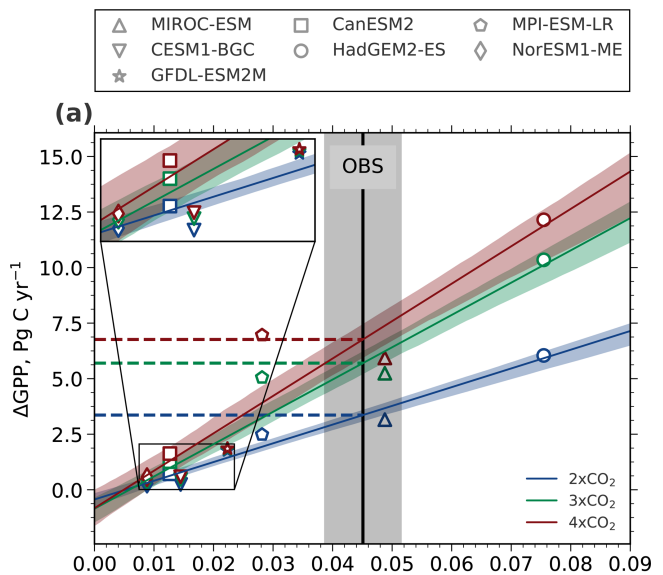

(b)

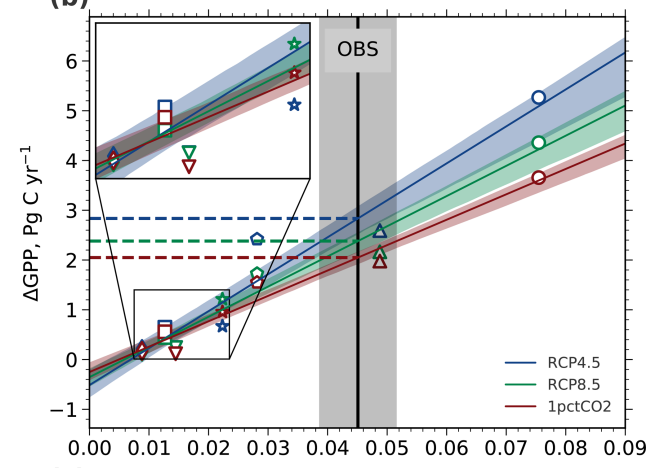
(c)

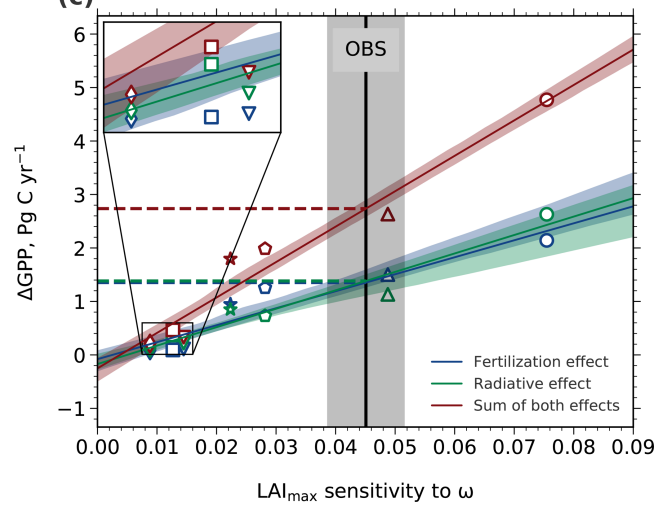

Figure 7. Linear relationships between the historical sensitivity of $\mathrm{LAI}_{\max }$ to $\omega$ and an absolute increase in GPP at different levels (a), different time rates (b), and the effects of rising $\mathrm{CO}_{2}$ (c). The solid black line depicts the observational sensitivity including the standard error (gray shading). Each CMIP5 model is represented by a distinct marker (legend at the top). The colored lines show the best linear fits including the $68 \%$ confidence interval estimated by bootstrapping across the model ensemble. The colored dashed lines indicate the derived constraints on $\triangle \mathrm{GPP}$. (a) Absolute changes in GPP at different levels of $\mathrm{CO}_{2}: 2 \times \mathrm{CO}_{2}$ (blue), $3 \times \mathrm{CO}_{2}$ (green), and $4 \times \mathrm{CO}_{2}$ (red). (b) Absolute changes in GPP for a rising $\mathrm{CO}_{2}$ concentration from 380 to $535 \mathrm{ppm}$ at different time rates: RCP4.5 (90-year, blue), RCP8.5 (45-year, green), and 1pctCO2 (30-year, red). (c) Absolute changes in GPP due to the two disentangled effects of $\mathrm{CO}_{2}$ at $2 \times \mathrm{CO}_{2}$ in idealized simulations: fertilization effect (esmFixClim1, blue), radiative effect (esmFdbk1, green), and the sum of both effects (red).

\section{Conclusions}

An in-depth analysis of the EC method is illustrated in this article through its application to projections of change in NHL photosynthesis under conditions of a rising atmospheric $\mathrm{CO}_{2}$ concentration. Key conclusions highlighting the functionality of the EC method are presented below.

The importance of how the observational predictor is obtained cannot be emphasized enough because the EC method is particularly sensitive to observational uncertainty. The single observational estimate essentially determines the EC, whereas the emergent linear relationship is established based on a collection of multi-model estimates (each model gets "one vote"; however, some models might be more influential than others; Bracegirdle and Stephenson, 2012b). Hence, the observational uncertainty has a much larger bearing on the EC than the uncertainty of each individual model. To overcome this source of uncertainty, various meaningful observations should be taken into consideration when establishing the observed predictor.

Spatially aggregating observations and model output at different resolutions in the EC method constitutes another source of uncertainty. Predictors and predictands expressed as regional estimates (e.g., area-weighted mean of the NHLs) are approximations of complex fine-scale processes. Aggregation will inevitably introduce a random error component due to the inclusion of estimates from areas where the predictor does not change or a systematic bias from areas where the predictor has a reversed sign. Thus, the spatially aggregated variables are meaningful only if most of the region is in agreement about the response to $\mathrm{CO}_{2}$ forcing (e.g., more than half of the NHLs is greening with rising $\mathrm{CO}_{2}$ ). However, we find that the source of uncertainty related to spatial aggregation is of minor importance as long as spatial variations in observations and model simulations are treated consistently.

A large source of uncertainty is associated with the temporal variability of the predictor variable when comparing models and observations. Establishing a robust predictor requires evaluating temporal window lengths of sufficient duration (approximately 30 years) and their locations along the forcing timeline. Both window length and location should match between models and observations in the EC method. For example, the analysis in Wenzel et al. (2016) might have yielded different results and conclusions if the model and observational predictor sensitivities were temporally matched. We find that the relevance of window length decreases with increasing and accelerating forcing, depending on the magnitude of the natural and/or internal variability (signal-to-noise ratio) of the predictor variable.

The level, effect, and time rate of applied $\mathrm{CO}_{2}$ forcing can have a bearing on the linear relationship between the predictand and predictor variables (Fig. 1). In our case study, the relationship underpinning the EC method, namely that between concurrent $\Delta \mathrm{GPP}$ and $\Delta \mathrm{LAI}_{\max }$, changes nonlinearly with an increasing forcing level (i.e., saturation with rising 
$\mathrm{CO}_{2}$ concentration). The EC method can still be applied because the CMIP5 models agree on the nonlinear behavior of the system. However, at very high $\mathrm{CO}_{2}$ concentrations the models diverge and this relation breaks down, at which point the EC method fails. The two dominant effects of a rising $\mathrm{CO}_{2}$ concentration on vegetation, namely fertilization and radiative effects, appear to be approximately additive in terms of GPP enhancement to $\mathrm{CO}_{2}$ forcing in the NHLs. Therefore, the EC method can be applied to constrain estimates of GPP due to one, the other, or both of the effects. The models, however, document a higher radiative effect than fertilization at concentrations exceeding $2 \times \mathrm{CO}_{2}$. Another intriguing conclusion from our analysis is that the time rate of forcing has an effect on GPP changes; that is, the projected GPP enhancement to $\mathrm{CO}_{2}$ forcing seems to be dependent on how the forcing is applied over time, as in different scenarios or RCPs. This aspect is presently not well understood and requires further study.

The EC framework is widely promoted as observationbased evaluation tool for climate projections, especially in the context of the nascent CMIP6 ensemble (Eyring et al., 2019; Hall et al., 2019). Previous EC studies, however, exclusively focused on predictor-predictand combinations that exhibit so-called existent ECs (Hall et al., 2019); i.e., the predictor and predictand are found to relate linearly across the ensemble. In the context of ESM evaluation, nonexistent ECs, for which the predictor and predictand are found to be unrelated in the ensemble, are equally important. Since predictor and predictand variables are premised on our mechanistic process understanding, nonexistent ECs reveal a fundamental disagreement on the system dynamics among the models. This study encourages researchers to scrutinize these system dynamics in the predictor-predictand space and also report such nonexistent, yet expected, ECs in order to advance model development and evaluation.
Across different disciplines each EC and its set of predictors and predictands are unique to some extent and require an individual detailed examination. In this article, we addressed general potential sources of uncertainty and limitations in the EC method by means of a case study in carbon cycle research. Thus, the illustrated results are qualitatively transmissible to other sets of predictors and predictands and are generally relevant in Earth system sciences.

Data availability. All data used in this study are available from public databases or literature, which can be found with the references provided in respective "Data and methods" section. Processed data are available from the corresponding author upon request or by contacting Carola Kauhs at carola.kauhs@mpimet.mpg.de. 
Appendix A

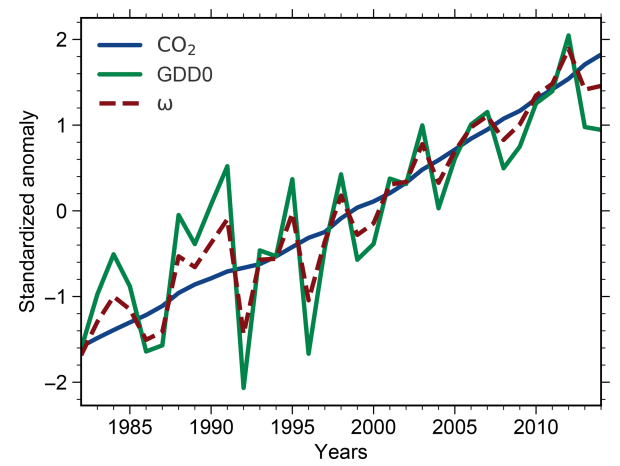

Figure A1. Standardized temporal anomalies of annual averaged atmospheric $\mathrm{CO}_{2}$ concentration (blue solid line), area-weighted averaged GDD0 for NHLs (green solid line), and their leading principal component $\omega$ (red dashed line) in observations.
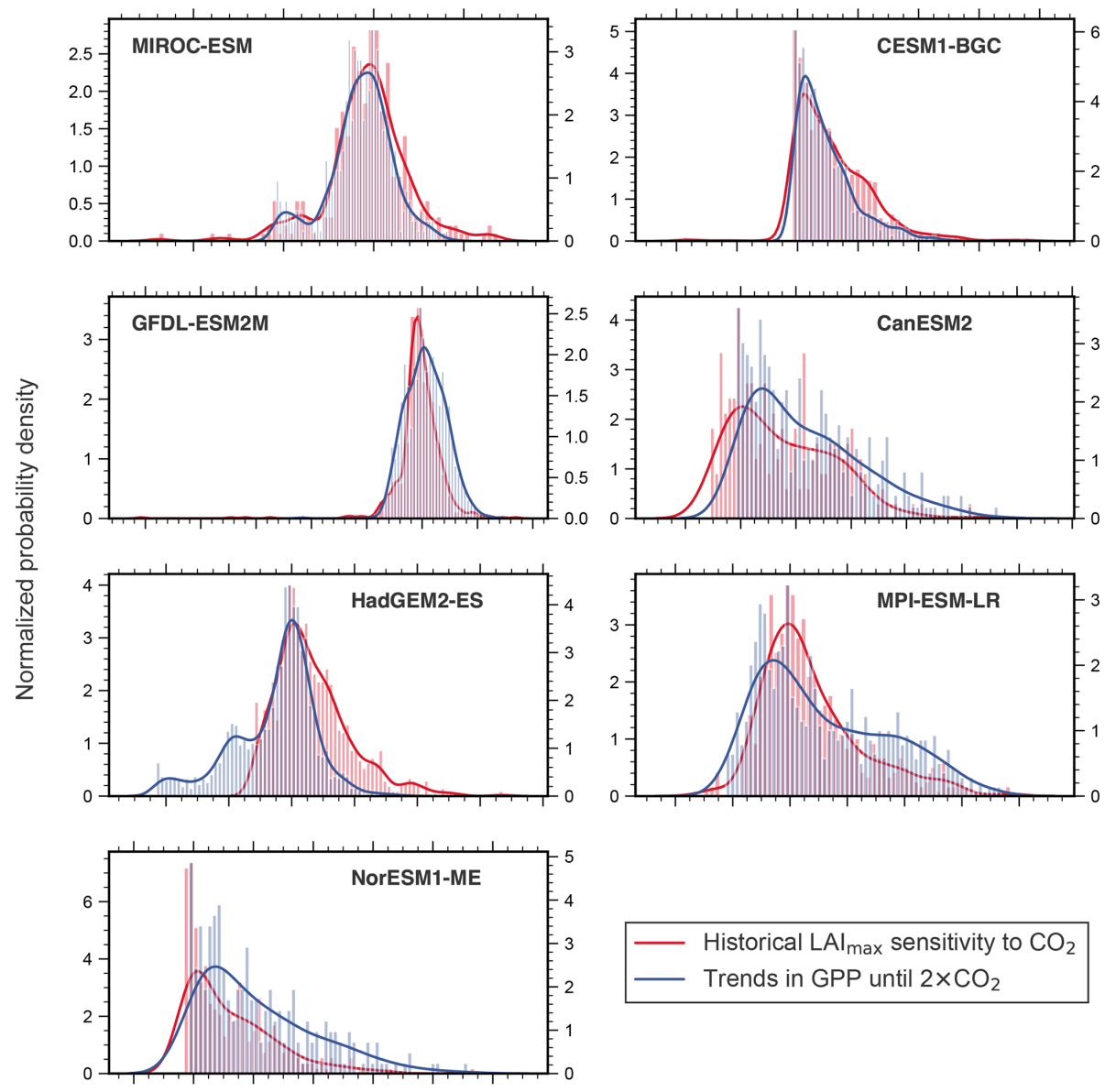

Normalized $x$ axis

Figure A2. Similar pixel distribution of the predictor and predictand in each model, except HadGEM2-ES. Histograms and associated probability density functions (Gaussian kernel density estimation) of LAI sensitivity to $\omega$ (red, left $y$ axis, historical simulations) and temporal trends in GPP (blue, right $y$ axis, 1pctCO2, until $2 \times \mathrm{CO}_{2}$ ) for NHLs are shown for all CMIP5 models. Only significant pixels are included (Mann-Kendall test, $p<0.1$ ). To obtain comparability between the distributions, the $x$ axis was normalized and has only a qualitative meaning. 
(a)

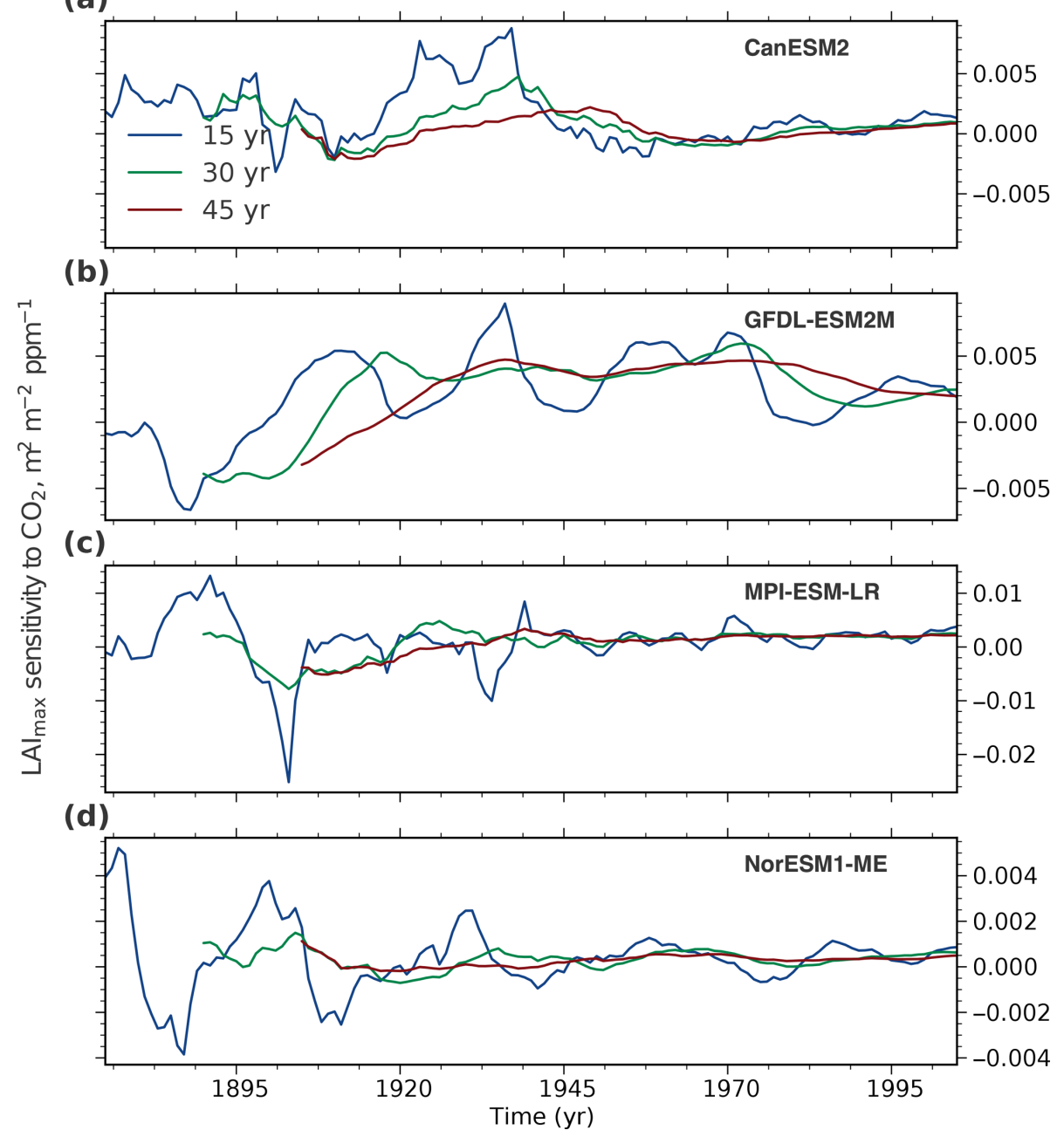

Figure A3. Temporal variation of LAI $I_{\max }$ sensitivity to $\omega$ in four CMIP5 models analogous to Fig. 4 . The colored lines show LAI $I_{\max }$ sensitivity variations for moving windows of varying length: 15 (blue), 30 (green), and 45 (red) years over the historical period from 1860 to 2005 . 
(a)

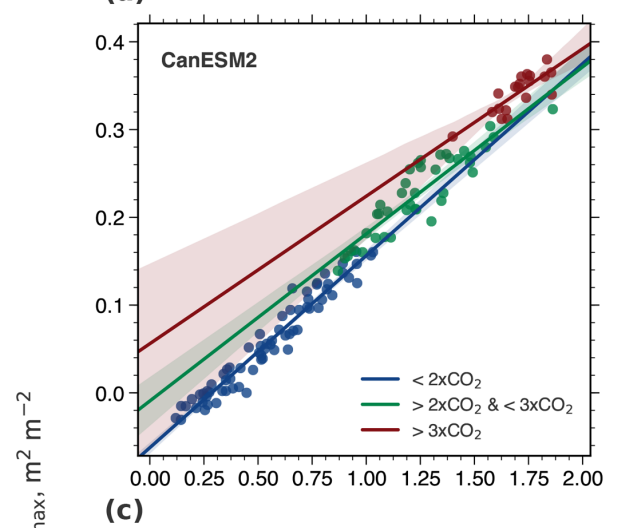

(c)

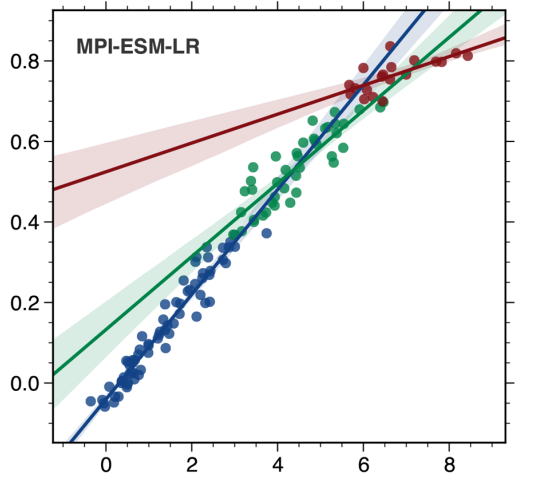

(b)

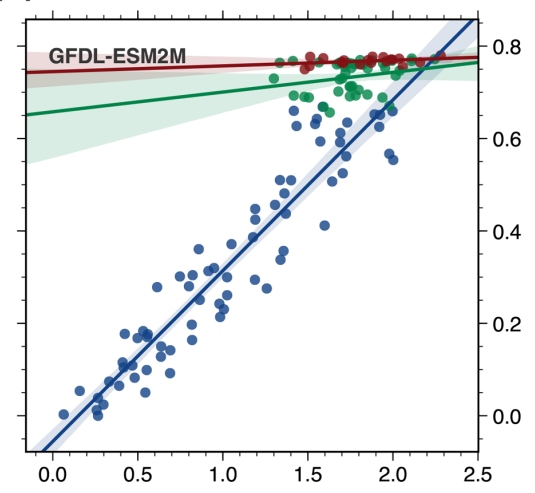

(d)

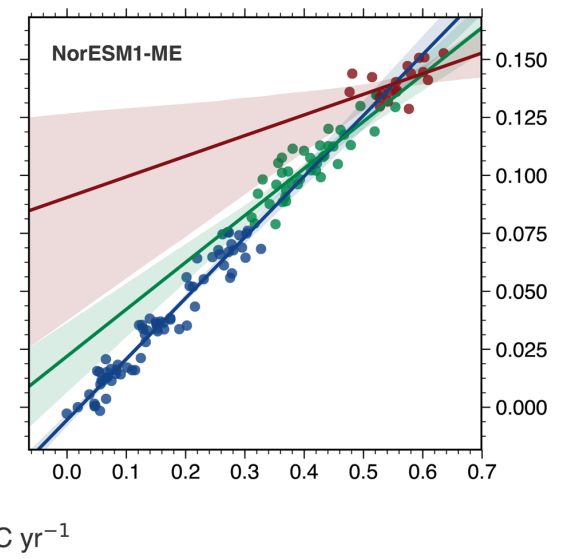

Figure A4. Correlation of $\triangle \mathrm{LAI}_{\max }$ and $\Delta \mathrm{GPP}$ with increasing $\mathrm{CO}_{2}$ forcing, starting from a preindustrial concentration of $280 \mathrm{ppm}(1 \times$ $\mathrm{CO}_{2}$ ) to $4 \times \mathrm{CO}_{2}$ (CMIP5 1pctCO2 simulations). Results are shown for four CMIP5 models analogous to Fig. 5. Blue colored dots show the relation between $1 \times \mathrm{CO}_{2}$ and $2 \times \mathrm{CO}_{2}$, green colored dots between $2 \times \mathrm{CO}_{2}$ and $3 \times \mathrm{CO}_{2}$, and red colored dots between $3 \times \mathrm{CO}_{2}$ and $4 \times \mathrm{CO}_{2}$. The respective colored lines represent the best linear fit through those dots and the shading represents the $95 \%$ confidence interval. 
(a)

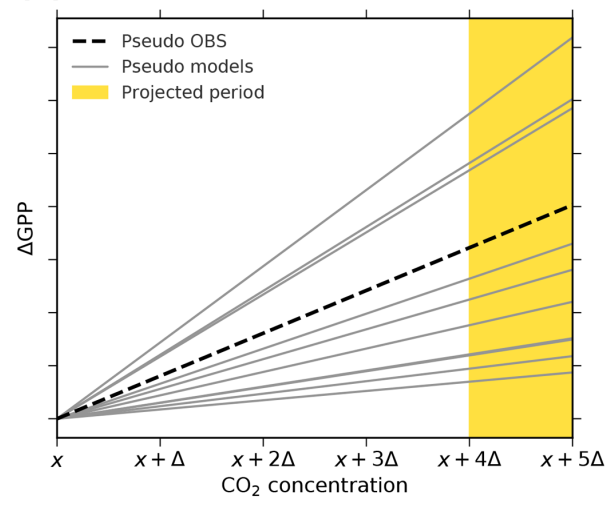

(c)

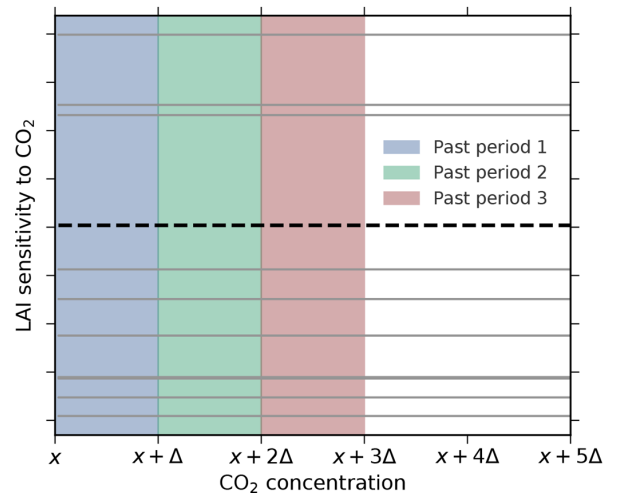

(b)

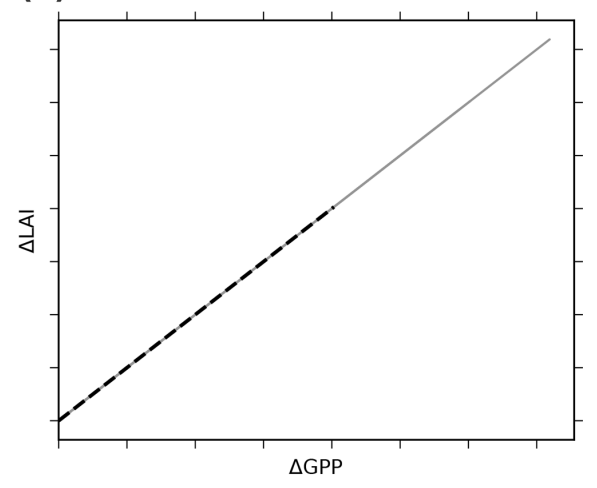

(d)

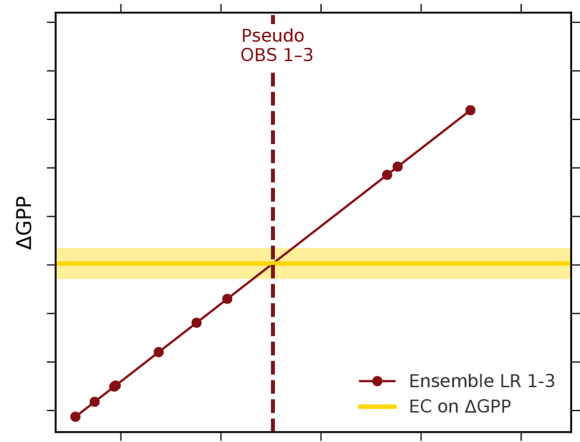

LAl sensitivity to $\mathrm{CO}_{2}$

Figure A5. Thought experiment to examine the applicability of the EC analysis assuming an idealized linear-linear behavior of the system (Case 1, Table A1). (a) Changes in GPP relate linearly to changes in $\mathrm{CO}_{2}$ concentration. The yellow band marks the projection period of interest, i.e., the period of $\mathrm{CO}_{2}$ concentration from $x+4 \Delta$ to $x+5 \Delta$. (b) Changes in LAI relate linearly to changes in GPP. The parameterization in the linear functions for pseudo observations (dashed black line) as well as models (solid gray lines) is determined randomly for each model. (c) The diagnostic variable, LAI sensitivity to $\mathrm{CO}_{2}$, remains constant with increasing $\mathrm{CO}_{2}$ as a consequence of the overall linear characteristics of the system. The colored bands indicate three "past" periods from $x$ to $x+\Delta$ (blue), $x+\Delta$ to $x+2 \Delta$ (green), and $x+2 \Delta$ to $x+3 \Delta$ (red). (d) Linear relationships among the pseudo model ensembles (Ensemble LR 1-3 on top of each other, red) between LAI sensitivity to $\mathrm{CO}_{2}$ of the three past periods and $\Delta \mathrm{GPP}$ from the projected period. Red dots mark different models and the dashed line represents associated pseudo observations for all three historical periods. The solid yellow line depicts the constant EC on projected $\Delta$ GPP irrespective of the past period. 
(a)

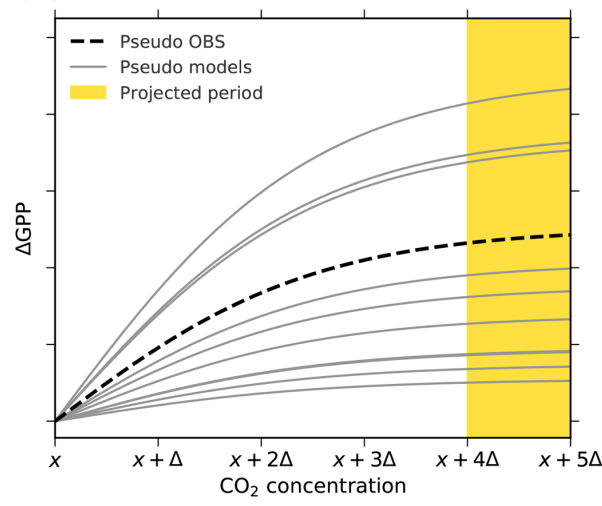

(c)

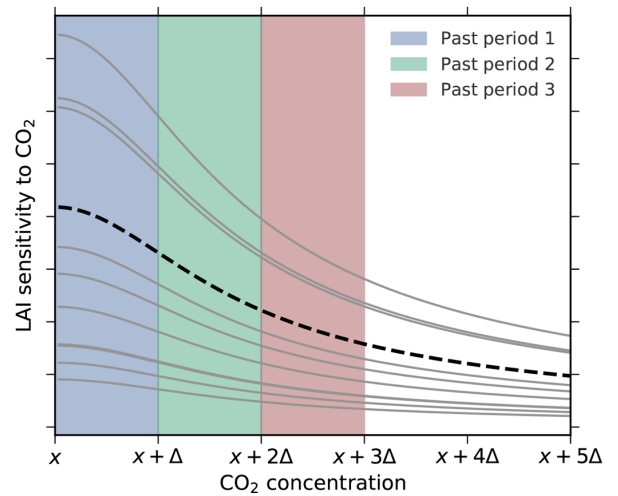

(b)

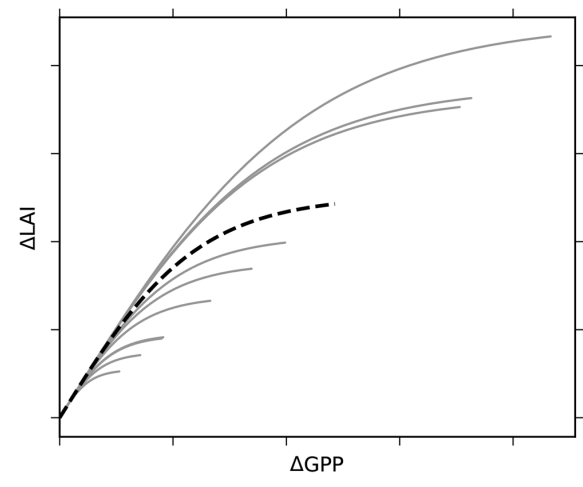

(d)

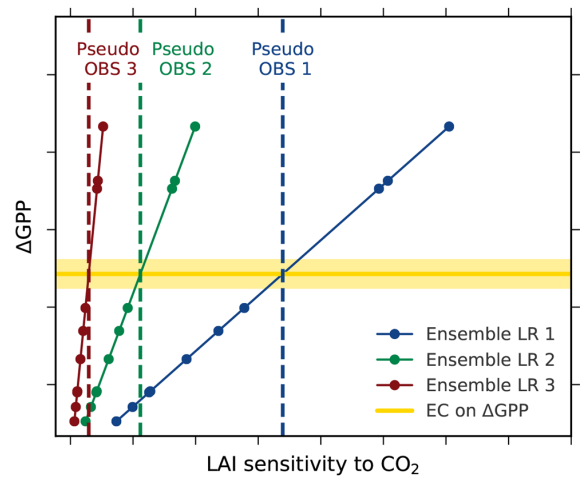

Figure A6. Thought experiment to examine the applicability of the EC analysis assuming an idealized nonlinear-nonlinear behavior of the system (Case 4, Table A1). (a) $\Delta$ GPP decreases with increasing $\mathrm{CO}_{2}$ concentration (described by a hyperbolic tangent function). The yellow band marks the projected period of interest, i.e., the period of $\mathrm{CO}_{2}$ concentration from $x+4 \Delta$ to $x+5 \Delta$. (b) Also, $\Delta \mathrm{LAI}$ decreases with increasing GPP (described by a hyperbolic tangent function). The parameterization in the hyperbolic tangent functions for pseudo observations (dashed black line) as well as models (solid gray lines) is determined randomly for each model. (c) The diagnostic variable, LAI sensitivity to $\mathrm{CO}_{2}$, decreases with increasing $\mathrm{CO}_{2}$ as a consequence of the overall saturating characteristics of the system. The colored bands indicate three "past" periods from $x$ to $x+\Delta$ (blue), $x+\Delta$ to $x+2 \Delta$ (green), and $x+2 \Delta$ to $x+3 \Delta$ (red). (d) Linear relationships among the pseudo model ensembles (Ensemble LR, colored lines) between LAI sensitivity to $\mathrm{CO}_{2}$ of the three past periods and $\Delta$ GPP from the projected period. Colored dots mark different models and the dashed lines represent associated pseudo observations for the respective historical period. The solid yellow line depicts the constant EC on projected $\Delta$ GPP irrespective of the past period. 
Table A1. Overview of four possible cases of interaction between forcing, nonobservable, and observable identified in the thought experiment: all linear, all nonlinear, and two mixed cases.

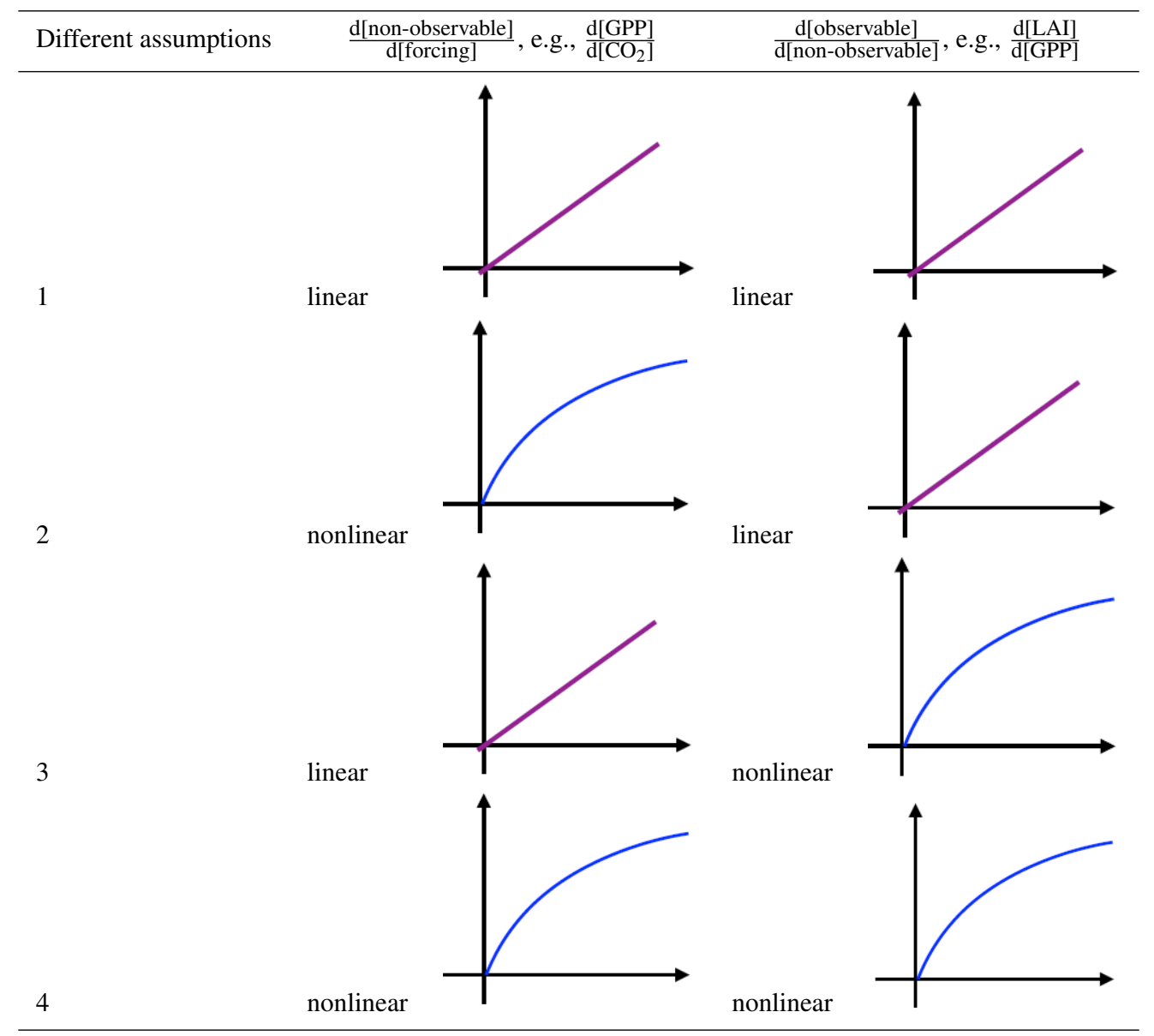


Author contributions. AJW performed the analysis. All authors contributed ideas and to writing the paper.

Competing interests. The authors declare that they have no conflict of interest.

Acknowledgements. We thankfully acknowledge Taejin Park and Chi Chen for their help with remote sensing data. We thank Gitta Lasslop for reviewing the paper. Ranga B. Myneni thanks the Alexander von Humboldt Foundation and NASA's Earth Science Division for making his participation in this research possible. Finally, we thank three anonymous reviewers and Vivek Arora, whose comments helped to substantially improve the paper.

Financial support. The article processing charges for this openaccess publication were covered by the Max Planck Society.

Review statement. This paper was edited by Vivek Arora and reviewed by three anonymous referees.

\section{References}

Anav, A., Friedlingstein, P., Kidston, M., Bopp, L., Ciais, P., Cox, P., Jones, C., Jung, M., Myneni, R., and Zhu, Z.: Evaluating the Land and Ocean Components of the Global Carbon Cycle in the CMIP5 Earth System Models, J. Climate, 26, 6801-6843, https://doi.org/10.1175/JCLI-D-12-00417.1, 2013.

Anav, A., Friedlingstein, P., Beer, C., Ciais, P., Harper, A., Jones, C., Murray-Tortarolo, G., Papale, D., Parazoo, N. C., Peylin, P., Piao, S., Sitch, S., Viovy, N., Wiltshire, A., and Zhao, M.: Spatiotemporal Patterns of Terrestrial Gross Primary Production: A Review, Rev. Geophys., 53, 785-818, https://doi.org/10.1002/2015RG000483, 2015.

Arora, V. K., Scinocca, J. F., Boer, G. J., Christian, J. R., Denman, K. L., Flato, G. M., Kharin, V. V., Lee, W. G., and Merryfield, W. J.: Carbon Emission Limits Required to Satisfy Future Representative Concentration Pathways of Greenhouse Gases, Geophys. Res. Lett., 38, L05805, https://doi.org/10.1029/2010GL046270, 2011.

Arora, V. K., Boer, G. J., Friedlingstein, P., Eby, M., Jones, C. D., Christian, J. R., Bonan, G., Bopp, L., Brovkin, V., Cadule, P., Hajima, T., Ilyina, T., Lindsay, K., Tjiputra, J. F., and $\mathrm{Wu}, \mathrm{T}$.: Carbon-Concentration and Carbon-Climate Feedbacks in CMIP5 Earth System Models, J. Climate, 26, 5289-5314, https://doi.org/10.1175/JCLI-D-12-00494.1, 2013.

Boé, J., Hall, A., and Qu, X.: September Sea-Ice Cover in the Arctic Ocean Projected to Vanish by 2100, Nat. Geosci., 2, 341-343, https://doi.org/10.1038/ngeo467, 2009.

Bracegirdle, T. J. and Stephenson, D. B.: Higher Precision Estimates of Regional Polar Warming by Ensemble Regression of Climate Model Projections, Clim. Dynam., 39, 2805-2821, https://doi.org/10.1007/s00382-012-1330-3, 2012a.

Bracegirdle, T. J. and Stephenson, D. B.: On the Robustness of Emergent Constraints Used in Multimodel Climate Change
Projections of Arctic Warming, J. Climate, 26, 669-678, https://doi.org/10.1175/JCLI-D-12-00537.1, 2012 b.

Cook, B. I. and Pau, S.: A Global Assessment of LongTerm Greening and Browning Trends in Pasture Lands Using the GIMMS LAI3g Dataset, Remote Sensing, 5, 2492-2512, https://doi.org/10.3390/rs5052492, 2013.

Cox, P. M., Pearson, D., Booth, B. B., Friedlingstein, P., Huntingford, C., Jones, C. D., and Luke, C. M.: Sensitivity of Tropical Carbon to Climate Change Constrained by Carbon Dioxide Variability, Nature, 494, 341-344, https://doi.org/10.1038/nature11882, 2013.

Cox, P. M., Huntingford, C., and Williamson, M. S.: Emergent Constraint on Equilibrium Climate Sensitivity from Global Temperature Variability, Nature, 553, 319-322, https://doi.org/10.1038/nature25450, 2018.

Eyring, V., Bony, S., Meehl, G. A., Senior, C. A., Stevens, B., Stouffer, R. J., and Taylor, K. E.: Overview of the Coupled Model Intercomparison Project Phase 6 (CMIP6) Experimental Design and Organization, Geosci. Model Dev., 9, 1937-1958, https://doi.org/10.5194/gmd-9-1937-2016, 2016.

Eyring, V., Cox, P. M., Flato, G. M., Gleckler, P. J., Abramowitz, G., Caldwell, P., Collins, W. D., Gier, B. K., Hall, A. D., Hoffman, F. M., Hurtt, G. C., Jahn, A., Jones, C. D., Klein, S. A., Krasting, J. P., Kwiatkowski, L., Lorenz, R., Maloney, E., Meehl, G. A., Pendergrass, A. G., Pincus, R., Ruane, A. C., Russell, J. L., Sanderson, B. M., Santer, B. D., Sherwood, S. C., Simpson, I. R., Stouffer, R. J., and Williamson, M. S.: Taking Climate Model Evaluation to the next Level, Nat. Clim. Change, 9, 102-110, https://doi.org/10.1038/s41558-018-0355-y, 2019.

Flato, G., Marotzke, J., Abiodun, B., Braconnot, P., Chou, S., Collins, W., Cox, P., Driouech, F., Emori, S., Eyring, V., Forest, C., Gleckler, P., Guilyardi, E., Jakob, C., Kattsov, V., Reason, C., and Rummukainen, M.: Evaluation of Climate Models, in: Climate Change 2013: The Physical Science Basis. Contribution of Working Group I to the Fifth Assessment Report of the Intergovernmental Panel on Climate Change, edited by: Stocker, T., Qin, D., Plattner, G.-K., Tignor, M., Allen, S., Boschung, J., Nauels, A., Xia, Y., Bex, V., and Midgley, P., Cambridge University Press, Cambridge, UK and New York, NY, USA, 741-866, 2013.

Forkel, M., Carvalhais, N., Rödenbeck, C., Keeling, R., Heimann, M., Thonicke, K., Zaehle, S., and Reichstein, M.: Enhanced Seasonal $\mathrm{CO}_{2}$ Exchange Caused by Amplified Plant Productivity in Northern Ecosystems, Science, 351, 696-699, https://doi.org/10.1126/science.aac4971, 2016.

Fritz, S., See, L., McCallum, I., You, L., Bun, A., Moltchanova, E., Duerauer, M., Albrecht, F., Schill, C., Perger, C., Havlik, P., Mosnier, A., Thornton, P., Wood-Sichra, U., Herrero, M., Becker-Reshef, I., Justice, C., Hansen, M., Gong, P., Abdel Aziz, S., Cipriani, A., Cumani, R., Cecchi, G., Conchedda, G., Ferreira, S., Gomez, A., Haffani, M., Kayitakire, F., Malanding, J., Mueller, R., Newby, T., Nonguierma, A., Olusegun, A., Ortner, S., Rajak, D. R., Rocha, J., Schepaschenko, D., Schepaschenko, M., Terekhov, A., Tiangwa, A., Vancutsem, C., Vintrou, E., Wenbin, W., van der Velde, M., Dunwoody, A., Kraxner, F., and Obersteiner, M.: Mapping Global Cropland and Field Size, Global Change Biol., 21, 1980-1992, https://doi.org/10.1111/GCB.12838, 2015. 
Goetz, S. J., Bunn, A. G., Fiske, G. J., and Houghton, R. A.: Satellite-Observed Photosynthetic Trends across Boreal North America Associated with Climate and Fire Disturbance, P. Natl. Acad. Sci. USA, 102, 13521-13525, https://doi.org/10.1073/pnas.0506179102, 2005.

Goll, D. S., Winkler, A. J., Raddatz, T., Dong, N., Prentice, I. C., Ciais, P., and Brovkin, V.: Carbon-Nitrogen Interactions in Idealized Simulations with JSBACH (Version 3.10), Geosci. Model Dev., 10, 2009-2030, https://doi.org/10.5194/gmd-102009-2017, 2017.

Graven, H. D., Keeling, R. F., Piper, S. C., Patra, P. K., Stephens, B. B., Wofsy, S. C., Welp, L. R., Sweeney, C., Tans, P. P., Kelley, J. J., Daube, B. C., Kort, E. A., Santoni, G. W., and Bent, J. D.: Enhanced Seasonal Exchange of $\mathrm{CO}_{2}$ by Northern Ecosystems Since 1960, Science, 341, 1085-1089, https://doi.org/10.1126/science.1239207, 2013.

Hall, A. and Qu, X.: Using the Current Seasonal Cycle to Constrain Snow Albedo Feedback in Future Climate Change, Geophys. Res. Lett., 33, L03502, https://doi.org/10.1029/2005GL025127, 2006.

Hall, A., Cox, P., Huntingford, C., and Klein, S.: Progressing Emergent Constraints on Future Climate Change, Nat. Clim. Change, 9, 269-278, https://doi.org/10.1038/S41558-019-0436-6, 2019.

Harris, I., Jones, P. D., Osborn, T. J., and Lister, D. H.: Updated High-Resolution Grids of Monthly Climatic Observations - the CRU TS3.10 Dataset, Int. J. Climatol., 34, 623-642, https://doi.org/10.1002/joc.3711, 2014.

Keeling, C. D., Chin, J. F. S., and Whorf, T. P.: Increased Activity of Northern Vegetation Inferred from Atmospheric $\mathrm{CO}_{2}$ Measurements, Nature, 382, 146-149, https://doi.org/10.1038/382146a0, 1996.

Keenan, T. F., Prentice, I. C., Canadell, J. G., Williams, C. A., Wang, H., Raupach, M., and Collatz, G. J.: Recent Pause in the Growth Rate of Atmospheric $\mathrm{CO}_{2}$ Due to Enhanced Terrestrial Carbon Uptake, Nat. Commun., 7, 13428, https://doi.org/10.1038/ncomms 13428, 2016.

Klein, S. A. and Hall, A.: Emergent Constraints for Cloud Feedbacks, Curr. Clim. Change Rep., 1, 276-287, https://doi.org/10.1007/s40641-015-0027-1, 2015.

Knutti, R.: The End of Model Democracy?, Climatic Change, 102, 395-404, https://doi.org/10.1007/s10584-010-9800-2, 2010.

Knutti, R., Sedláček, J., Sanderson, B. M., Lorenz, R., Fischer, E. M., and Eyring, V.: A Climate Model Projection Weighting Scheme Accounting for Performance and Interdependence, Geophys. Res. Lett., 44, 1909-1918, https://doi.org/10.1002/2016GL072012, 2017.

Kwiatkowski, L., Bopp, L., Aumont, O., Ciais, P., Cox, P. M., Laufkötter, C., Li, Y., and Séférian, R.: Emergent Constraints on Projections of Declining Primary Production in the Tropical Oceans, Nat. Clim. Change, 7, 355-358, https://doi.org/10.1038/nclimate3265, 2017.

Leakey, A. D. B., Ainsworth, E. A., Bernacchi, C. J., Rogers, A., Long, S. P., and Ort, D. R.: Elevated $\mathrm{CO}_{2}$ Effects on Plant Carbon, Nitrogen, and Water Relations: Six Important Lessons from FACE, J. Exp. Bot., 60, 2859-2876, https://doi.org/10.1093/jxb/erp096, 2009.

Lian, X., Piao, S., Huntingford, C., Li, Y., Zeng, Z., Wang, X., Ciais, P., McVicar, T. R., Peng, S., Ottlé, C., Yang, H., Yang, Y., Zhang, Y., and Wang, T.: Partitioning Global Land Evapotranspiration
Using CMIP5 Models Constrained by Observations, Nat. Clim. Change, 8, 640-646, https://doi.org/10.1038/s41558-018-02079, 2018.

Mahowald, N., Lo, F., Zheng, Y., Harrison, L., Funk, C., Lombardozzi, D., and Goodale, C.: Projections of Leaf Area Index in Earth System Models, Earth Syst. Dynam., 7, 211-229, https://doi.org/10.5194/esd-7-211-2016, 2016.

Mao, J., Ribes, A., Yan, B., Shi, X., Thornton, P. E., Séférian, R., Ciais, P., Myneni, R. B., Douville, H., Piao, S., Zhu, Z., Dickinson, R. E., Dai, Y., Ricciuto, D. M., Jin, M., Hoffman, F. M., Wang, B., Huang, M., and Lian, X.: Human-Induced Greening of the Northern Extratropical Land Surface, Nat. Clim. Change, 6, 959-963, https://doi.org/10.1038/nclimate3056, 2016.

Myneni, R. B., Keeling, C. D., Tucker, C. J., Asrar, G., and Nemani, R. R.: Increased Plant Growth in the Northern High Latitudes from 1981 to 1991, Nature, 386, 698-702, https://doi.org/10.1038/386698a0, 1997a.

Myneni, R. B., Ramakrishna, R., Nemani, R., and Running, S.: Estimation of Global Leaf Area Index and Absorbed Par Using Radiative Transfer Models, IEEE T. Geosci. Remote, 35, 13801393, https://doi.org/10.1109/36.649788, 1997 b.

Myneni, R. B., Hoffman, S., Knyazikhin, Y., Privette, J. L., Glassy, J., Tian, Y., Wang, Y., Song, X., Zhang, Y., Smith, G. R., Lotsch, A., Friedl, M., Morisette, J. T., Votava, P., Nemani, R. R., and Running, S. W.: Global Products of Vegetation Leaf Area and Fraction Absorbed PAR from Year One of MODIS Data, Remote Sens. Environ., 83, 214-231, https://doi.org/10.1016/S00344257(02)00074-3, 2002.

Nemani, R. R., Keeling, C. D., Hashimoto, H., Jolly, W. M., Piper, S. C., Tucker, C. J., Myneni, R. B., and Running, S. W.: Climate-Driven Increases in Global Terrestrial Net Primary Production from 1982 to 1999, Science, 300, 1560-1563, https://doi.org/10.1126/science.1082750, 2003.

Olson, D. M., Dinerstein, E., Wikramanayake, E. D., Burgess, N. D., Powell, G. V. N., Underwood, E. C., D'amico, J. A., Itoua, I., Strand, H. E., Morrison, J. C., Loucks, C. J., Allnutt, T. F., Ricketts, T. H., Kura, Y., Lamoreux, J. F., Wettengel, W. W., Hedao, P., and Kassem, K. R.: Terrestrial Ecoregions of the World: A New Map of Life on Earth, BioScience, 51, 933-938, https://doi.org/10.1641/00063568(2001)051[0933:TEOTWA]2.0.CO;2, 2001.

Park, T., Ganguly, S., Tømmervik, H., Euskirchen, E. S., Høgda, K.-A., Karlsen, S. R., Brovkin, V., Nemani, R. R., and Myneni, R. B.: Changes in Growing Season Duration and Productivity of Northern Vegetation Inferred from LongTerm Remote Sensing Data, Environ. Res. Lett., 11, 084001, https://doi.org/10.1088/1748-9326/11/8/084001, 2016.

Piao, S., Nan, H., Huntingford, C., Ciais, P., Friedlingstein, P., Sitch, S., Peng, S., Ahlström, A., Canadell, J. G., Cong, N., Levis, S., Levy, P. E., Liu, L., Lomas, M. R., Mao, J., Myneni, R. B., Peylin, P., Poulter, B., Shi, X., Yin, G., Viovy, N., Wang, T., Wang, X., Zaehle, S., Zeng, N., Zeng, Z., and Chen, A.: Evidence for a Weakening Relationship between Interannual Temperature Variability and Northern Vegetation Activity, Nat. Commun., 5, 5018, https://doi.org/10.1038/ncomms6018, 2014.

Pinzon, J. E. and Tucker, C. J.: A Non-Stationary 1981-2012 AVHRR NDVI3g Time Series, Remote Sensing, 6, 6929-6960, https://doi.org/10.3390/rs6086929, 2014. 
Poulter, B., Frank, D., Ciais, P., Myneni, R. B., Andela, N., Bi, J., Broquet, G., Canadell, J. G., Chevallier, F., Liu, Y. Y., Running, S. W., Sitch, S., and van der Werf, G. R.: Contribution of Semi-Arid Ecosystems to Interannual Variability of the Global Carbon Cycle, Nature, 509, 600-603, https://doi.org/10.1038/nature13376, 2014.

$\mathrm{Qu}, \mathrm{X}$. and Hall, A.: On the Persistent Spread in Snow-Albedo Feedback, Clim. Dynam., 42, 69-81, https://doi.org/10.1007/s00382-013-1774-0, 2014.

Sherwood, S. C., Bony, S., and Dufresne, J.-L.: Spread in Model Climate Sensitivity Traced to Atmospheric Convective Mixing, Nature, 505, 37-42, https://doi.org/10.1038/nature12829, 2014.

Stephenson, D. B., Collins, M., Rougier, J. C., and Chandler, R. E.: Statistical Problems in the Probabilistic Prediction of Climate Change, Environmetrics, 23, 364-372, https://doi.org/10.1002/env.2153, 2012.

Taylor, K. E., Stouffer, R. J., and Meehl, G. A.: An Overview of Cmip5 and the Experiment Design, B. Am. Meteorol. Soc., 93, 485-498, https://doi.org/10.1175/BAMS-D-11-00094.1, 2012.

van Vuuren, D. P., Edmonds, J., Kainuma, M., Riahi, K., Thomson, A., Hibbard, K., Hurtt, G. C., Kram, T., Krey, V., Lamarque, J.-F., Masui, T., Meinshausen, M., Nakicenovic, N., Smith, S. J., and Rose, S. K.: The Representative Concentration Pathways: An Overview, Climatic Change, 109, 5-31, https://doi.org/10.1007/s10584-011-0148-z, 2011.

Wang, J., Zeng, N., Liu, Y., and Bao, Q.: To What Extent Can Interannual $\mathrm{CO}_{2}$ Variability Constrain Carbon Cycle Sensitivity to Climate Change in CMIP5 Earth System Models?, Geophys. Res. Lett., 41, 3535-3544, https://doi.org/10.1002/2014GL060004, 2014.

Wenzel, S., Cox, P. M., Eyring, V., and Friedlingstein, P.: Emergent Constraints on Climate-Carbon Cycle Feedbacks in the CMIP5 Earth System Models, J. Geophys. Res.-Biogeo., 119, 794-807, https://doi.org/10.1002/2013JG002591, 2014.

Wenzel, S., Eyring, V., Gerber, E. P., and Karpechko, A. Y.: Constraining Future Summer Austral Jet Stream Positions in the CMIP5 Ensemble by Process-Oriented Multiple Diagnostic Regression, J. Climate, 29, 673-687, https://doi.org/10.1175/JCLID-15-0412.1, 2015.
Wenzel, S., Cox, P. M., Eyring, V., and Friedlingstein, P.: Projected Land Photosynthesis Constrained by Changes in the Seasonal Cycle of Atmospheric $\mathrm{CO}_{2}$, Nature, 538, 499-501, https://doi.org/10.1038/nature19772, 2016.

Winkler, A. J., Myneni, R. B., Alexandrov, G. A., and Brovkin, V.: Earth System Models Underestimate Carbon Fixation by Plants in the High Latitudes, Nat. Commun., 10, 885, https://doi.org/10.1038/S41467-019-08633-Z, 2019.

Yan, K., Park, T., Yan, G., Chen, C., Yang, B., Liu, Z., Nemani, R. R., Knyazikhin, Y., and Myneni, R. B.: Evaluation of MODIS LAI/FPAR Product Collection 6. Part 1: Consistency and Improvements, Remote Sensing, 8, 359, https://doi.org/10.3390/rs8050359, 2016a.

Yan, K., Park, T., Yan, G., Liu, Z., Yang, B., Chen, C., Nemani, R. R., Knyazikhin, Y., and Myneni, R. B.: Evaluation of MODIS LAI/FPAR Product Collection 6. Part 2: Validation and Intercomparison, Remote Sensing, 8, 460, https://doi.org/10.3390/rs8060460, 2016 b.

Zhu, Z., Bi, J., Pan, Y., Ganguly, S., Anav, A., Xu, L., Samanta, A., Piao, S., Nemani, R. R., and Myneni, R. B.: Global Data Sets of Vegetation Leaf Area Index (LAI)3g and Fraction of Photosynthetically Active Radiation (FPAR)3g Derived from Global Inventory Modeling and Mapping Studies (GIMMS) Normalized Difference Vegetation Index (NDVI3g) for the Period 1981 to 2011, Remote Sensing, 5, 927-948, https://doi.org/10.3390/rs5020927, 2013.

Zhu, Z., Piao, S., Myneni, R. B., Huang, M., Zeng, Z., Canadell, J. G., Ciais, P., Sitch, S., Friedlingstein, P., Arneth, A., Cao, C., Cheng, L., Kato, E., Koven, C., Li, Y., Lian, X., Liu, Y., Liu, R., Mao, J., Pan, Y., Peng, S., Peñuelas, J., Poulter, B., Pugh, T. A. M., Stocker, B. D., Viovy, N., Wang, X., Wang, Y., Xiao, Z., Yang, H., Zaehle, S., and Zeng, N.: Greening of the Earth and Its Drivers, Nat. Clim. Change, 6, 791-795, https://doi.org/10.1038/nclimate3004, 2016. 